ARTICLE

Received 22 May 2013 | Accepted 3 Sep 2013 | Published 7 Oct 2013 DOl: 10.1038/ncomms3540

\title{
Bio-inspired voltage-dependent calcium channel blockers
}

Tingting Yang ${ }^{1, \star}$, Lin-Ling $\mathrm{He}^{1, \star}$, Ming Chen ${ }^{1}$, Kun Fang ${ }^{1} \&$ Henry M. Colecraft ${ }^{1}$

$\mathrm{Ca}^{2}+$ influx via voltage-dependent $\mathrm{Ca}_{v} 1 / \mathrm{Ca}_{\vee} 2$ channels couples electrical signals to biological responses in excitable cells. Cav1/Cav2 channel blockers have broad biotechnological and therapeutic applications. Here we report a general method for developing novel genetically encoded calcium channel blockers inspired by Rem, a small G-protein that constitutively inhibits $\mathrm{Ca}_{\vee} 1 / \mathrm{Ca}_{\vee} 2$ channels. We show that diverse cytosolic proteins ( $\mathrm{Ca}_{\vee} \beta$, 14-3-3, calmodulin and (aMKII) that bind pore-forming $\alpha_{1}$-subunits can be converted into calcium channel blockers with tunable selectivity, kinetics and potency, simply by anchoring them to the plasma membrane. We term this method 'channel inactivation induced by membrane-tethering of an associated protein' (ChIMP). ChIMP is potentially extendable to small-molecule drug discovery, as engineering FK506-binding protein into intracellular sites within Cav1.2- $\alpha_{1 c}$ permits heterodimerization-initiated channel inhibition with rapamycin. The results reveal a universal method for developing novel calcium channel blockers that may be extended to develop probes for a broad cohort of unrelated ion channels.

\footnotetext{
${ }^{1}$ Department of Physiology and Cellular Biophysics, Columbia University, College of Physicians and Surgeons, 1150 St Nicholas Avenue, New York, New York 10032, USA. *These authors contributed equally to this work. Correspondence and requests for materials should be addressed to H.M.C. (email: hc2405@columbia.edu).
} 
igh-voltage-activated $\mathrm{Ca}^{2+}\left(\mathrm{Ca}_{\mathrm{V}} 1 / \mathrm{Ca}_{\mathrm{V}} 2\right)$ channels convert membrane electrical signals into $\mathrm{Ca}^{2+}$ influx that drives essential processes ranging from muscle contraction to synaptic transmission ${ }^{1} . \mathrm{Ca}_{\mathrm{V}} 1 / \mathrm{Ca}_{\mathrm{V}} 2$ channels are hetero-multimers comprised minimally of any one of seven pore-forming $\alpha_{1}\left(\mathrm{Ca}_{\mathrm{V}} 1.1-\mathrm{Ca}_{\mathrm{V}} 1.4 ; \mathrm{Ca}_{\mathrm{V}} 2.1-\mathrm{Ca}_{\mathrm{V}} 2.3\right)$, four $\mathrm{Ca}_{\mathrm{V}} \beta$ $\left(\mathrm{Ca}_{\mathrm{V}} \beta_{1}-\beta_{4}\right)$ and four $\alpha_{2} \delta\left(\alpha_{2} \delta 1-\alpha_{2} \delta 4\right)$ subunits in a $1: 1: 1$ ratio $^{1,2}$. $\mathrm{Ca}_{\mathrm{V}} 1 / \mathrm{Ca}_{\mathrm{V}} 2$ channel inhibition is an important or potential therapy for serious disorders including hypertension, neuropathic pain, stroke, Alzheimer's and Parkinson's disease ${ }^{3-6}$. L-type calcium $\left(\mathrm{Ca}_{\mathrm{V}} 1.1-1.4\right)$ channels are inhibited by dihydropyridines, phenylalkylamines and benzothiazepines, whereas $\mathrm{Ca}_{\mathrm{V}} 2.1-2.3$ channels are blocked by distinct venom toxins ${ }^{8}$. Nevertheless, the full potential of calcium channel blocker (CCB) therapy remains unrealized due to a lack of selective and tissue-specific smallmolecule inhibitors for individual $\mathrm{Ca}_{\mathrm{V}} 1 / \mathrm{Ca}_{\mathrm{V}} 2$ channel types. For example, clinically used L-type CCBs do not discriminate effectively among $\mathrm{Ca}_{\mathrm{V}} 1.1-\mathrm{Ca}_{\mathrm{V}} 1.4$ isoforms ${ }^{9}$. As L-type channels are widely expressed, this raises significant concerns for off-target effects when targeting specific $\mathrm{Ca}_{\mathrm{V}} 1$ isoforms for neurological disorders such as Alzheimer's and Parkinson's diseases ${ }^{3,5}$. Genetically encoded intracellular-acting CCBs have the potential for a high therapeutic index because they can be expressed in a locally restricted manner ${ }^{2,10}$.

RGK (Rad/Rem/Rem2/Gem/Kir) GTPases are monomeric Raslike G-proteins that powerfully inhibit all $\mathrm{Ca}_{\mathrm{V}} 1 / \mathrm{Ca}_{\mathrm{V}} 2$ channels ${ }^{11-13}$. Two proof-of-concept experiments have demonstrated the potential powerful applications of RGK proteins as genetically encoded CCBs. First, local gene delivery of Gem to the atrioventricular node slowed atrioventricular nodal conduction and reduced heart rate in a porcine atrial fibrillation model ${ }^{10}$. Second, targeting Rem to caveolae in single cardiomyocytes permitted selective inhibition of $\mathrm{Ca}_{\mathrm{V}} 1.2$ channels in this sub-cellular compartment ${ }^{14}$. The ability to inhibit $\mathrm{Ca}_{\mathrm{V}} 1 / \mathrm{Ca}_{\mathrm{V}} 2$ channels in such a locally restricted manner at the whole organ or single-cell level cannot be achieved with traditional small-molecule CCBs. Ultimately, however, the potential applications of RGKs themselves as genetically encoded CCBs are limited because they do not discriminate among $\mathrm{Ca}_{\mathrm{V}} 1 / \mathrm{Ca}_{\mathrm{V}} 2$ isoforms, and they have other diverse binding partners and biological functions including regulating the cytoskeleton ${ }^{11,15,16}$. These challenges may be overcome if it were possible to exploit the mechanism of action of RGKs to derive general principles for designing novel CCBs. Here we achieve this objective inspired by insights into how the RGK protein, Rem, inhibits $\mathrm{Ca}_{\mathrm{V}} 1 / \mathrm{Ca}_{\mathrm{V}} 2$ channels.

\section{Results}

Differential tuning of $\mathrm{Ca}_{V} 1 / \mathrm{Ca}_{V} 2$ channels by engineered Rem. Wild-type Rem targets to the plasma membrane using a polybasic $\mathrm{C}$ terminus tail and constitutively inhibits all $\mathrm{Ca}_{\mathrm{V}} 1$ and $\mathrm{Ca}_{\mathrm{V}} 2$ channel isoforms. Deleting the Rem C terminus tail $\left(\operatorname{Rem}_{265}\right)$ ablates both membrane targeting and $I_{\mathrm{Ca}}$ inhibition. We previously discovered that fusing the $\mathrm{C} 1$ domain from protein kinase $\mathrm{C} \gamma\left(\mathrm{C}_{\mathrm{PKC}}\right)$ to $\mathrm{Rem}_{1-265}$ enables it to be dynamically recruited to the plasma membrane with the phorbol ester, phorbol-12,13dibutyrate $(\mathrm{PdBu})$, resulting in concomitant inhibition of $I_{\mathrm{Ca}}$. A surprising, but potentially fortuitous, feature of $\mathrm{Ca}_{\mathrm{V}}$ channel inhibition by $\mathrm{Rem}_{265}-\mathrm{Cl}_{\mathrm{PKC}}$ was that it displayed apparent selectivity, being effective for $\mathrm{Ca}_{\mathrm{V}} 1.2$ and $\mathrm{Ca}_{\mathrm{V}} 2.2$, but inert against $\mathrm{Ca}_{\mathrm{V}} 2.1$ and $\mathrm{Ca}_{\mathrm{V}} 2.3$. As a prelude to investigating whether the mechanism of Rem inhibition of $\mathrm{Ca}_{V} 1 / \mathrm{Ca}_{V} 2$ channels could be exploited to develop a general method for developing genetically encoded CCBs, we explored the possibility of tuning the selectivity and potency of PdBu-inducible Rem-based CCBs by varying the relative positioning of the $C 1_{\mathrm{PKC}}$ motif in truncated
Rem (Fig. 1a). When expressed in HEK 293 cells, all the truncated-Rem/C1 $1_{\mathrm{PKC}}$ fusion proteins are basally cytosolic and are rapidly recruited to the plasma membrane with PdBu (Fig. 1b,c). Under basal conditions, robust whole-cell currents were recorded from cells co-expressing distinct $\mathrm{Ca}_{\mathrm{V}} 1 / \mathrm{Ca}_{\mathrm{V}} 2$ channel subunits $\left(\alpha_{1}+\beta\right)$ and the different Rem/C1 $1_{\mathrm{PKC}}$ fusion constructs, enabling their selectivity and potency to be tested by adding $1 \mu \mathrm{M} \mathrm{PdBu}$ (Fig. 1d-g). Surprisingly, subtle differences in the relative position of $\mathrm{C} 1_{\mathrm{PKC}}$ in truncated Rem dramatically impacted the comparative effectiveness of the resulting protein for $\mathrm{Ca}_{\mathrm{V}} 2.1$ and $\mathrm{Ca}_{\mathrm{V}} 2.2$ channels. For example, CFP-Rem $1-265-\mathrm{Cl}_{\mathrm{PKC} \gamma}$ inhibited $\mathrm{Ca}_{\mathrm{V}} 2.2$ (and $\mathrm{Ca}_{\mathrm{V}} 1.2$ ) channels in response to $\mathrm{PdBu}$, but was ineffective on $\mathrm{Ca}_{\mathrm{V}} 2.1$ (Fig. 1d,h). In sharp contrast, simply shifting the $\mathrm{C}_{\mathrm{PKC}}$ motif 15 residues closer to the $\mathrm{G}$-domain produced CFP-Rem $1-250-\mathrm{C}_{\mathrm{PKC} \gamma}$, which permitted $\mathrm{PdBu}$ induced inhibition of $\mathrm{Ca}_{\mathrm{V}} 2.1$ (and $\mathrm{Ca}_{\mathrm{V}} 1.2$ ) but was inert against $\mathrm{Ca}_{\mathrm{V}} 2.2$ (Fig. 1e,h). Similarly, whereas $\mathrm{C1}_{\mathrm{PKC}^{-}}$YFP-Rem $1-265$ was effective for $\mathrm{Ca}_{\mathrm{V}} 2.2$ but not $\mathrm{Ca}_{\mathrm{V}} 2.1$ (Fig. 1f,h), $\mathrm{Cl}_{\mathrm{PKC}^{-}-\mathrm{Rem}_{78-265^{-}}}$ CFP had the opposite preference, with selectivity for $\mathrm{Ca}_{\mathrm{V}} 2.1$ over $\mathrm{Ca}_{\mathrm{V}} 2.2$ (Fig. 1g,h). By contrast with the tunable selectivity for $\mathrm{Ca}_{V} 2.2 / \mathrm{Ca}_{V} 2.1$ channels, $\mathrm{Ca}_{V} 1.2$ was uniformly sensitive to all four truncated-Rem/C1 $1_{\mathrm{PKC}}$ constructs. Overall, these results provide the novel observation that selectivity for distinct $\mathrm{Ca}_{\mathrm{V}} 2$ channels can be engineered into Rem-based CCBs simply by altering the relative positioning of the inducible membraneanchoring domain.

Conversion of auxiliary $\mathrm{Ca}_{\mathrm{V}} \boldsymbol{\beta}_{3}$ into a $\mathrm{Ca}_{\mathrm{V}}$ channel inhibitor. How does Rem binding to the plasma membrane result in $\mathrm{Ca}_{\mathrm{V}}$ channel inhibition, and can this mechanism be exploited to identify a general method for developing genetically encoded CCBs? A critical clue for these questions is that in addition to membrane targeting (Fig. 1), binding to auxiliary $\mathrm{Ca}_{V} \beta$ subunits is also required for $\mathrm{Ca}_{\mathrm{V}} 1.2$ channel inhibition by CFP- $\mathrm{Rem}_{1-265^{-}}$ $\mathrm{C}_{\mathrm{PKC}^{17-19}}$. $\mathrm{Ca}_{\mathrm{V}} \beta \mathrm{s}$ bind the intracellular domain I-II loop of pore-forming $\alpha_{1}$-subunits and promote channel trafficking to the plasma membrane, as well as modulating channel activation and inactivation gating ${ }^{20}$. To explain the dual requirement of membrane targeting and $\beta$ binding for Rem inhibition of $\mathrm{Ca}_{\mathrm{V}} 1.2$ open probability $\left(P_{\mathrm{o}}\right)$, we hypothesized that though cytosolic variants of Rem constitutively associate with $\mathrm{Ca}_{V} \beta$ s in $\mathrm{Ca}_{\mathrm{V}} 1 / \mathrm{Ca}_{\mathrm{V}} 2$ channel complexes, they are functionally silent, allowing the channel to gate and conduct current normally with depolarization (Fig. 2a, top left). By contrast, membrane-targeted Rem 'tugs' on $\mathrm{Ca}_{\mathrm{V}} \beta$ and by extension, the associated $\alpha_{1}$-subunit I-II loop, inducing a conformational change that closes the channel pore (Fig. 2a, top right). This allosteric model predicts it should be possible to convert the normally stimulatory $\mathrm{Ca}_{V} \beta$ into a $\mathrm{Ca}_{\mathrm{V}}$ channel inhibitor by directly inducing its association with the plasma membrane (Fig. 2a, bottom). We tested this idea by fusing $\mathrm{C}_{\mathrm{PKC}}$ directly to the $\mathrm{C}$ terminus of $\mathrm{CFP}-\beta_{3}$ (Fig. $2 \mathrm{~b}$ ). CFP$\beta_{3}-\mathrm{Cl}_{\mathrm{PKC} \gamma}$ is basally cytosolic but is rapidly recruited to the plasma (and nuclear) membrane with $1 \mu \mathrm{M}$ PdBu (Fig. 2b, bottom left). When co-expressed with $\mathrm{Ca}_{\mathrm{V}} 2.2\left(\alpha_{1 \mathrm{~B}}\right), \mathrm{CFP}-\beta_{3}-\mathrm{C}_{\mathrm{PKC} \gamma}$ supported robust basal $\mathrm{Ba}^{2+}$ current $\left(I_{\mathrm{Ba}}\right)$, signifying a retained ability to promote $\alpha_{1}$-subunit membrane-trafficking and modulate gating (Fig. 2c). Remarkably, exposure to $1 \mu \mathrm{M} \mathrm{PdBu}$ resulted in a gradual decrease of $I_{\mathrm{Ba}}$, peaking at $50 \%$ inhibition after $5 \mathrm{~min}$ (Fig. 2c, middle). The decrease in $I_{\mathrm{Ba}}$ extended across all relevant test pulse potentials, with no shift in the current density-voltage $(I-V)$ relationship (Fig. 2c, right). Importantly, control cells expressing $\alpha_{1 \mathrm{~B}}+$ wild type (WT) $\beta$ are not blocked by $\mathrm{PdBu}^{18}$ (Supplementary Fig. S1). Therefore, directly anchoring $\mathrm{CFP}-\beta_{3}-\mathrm{C} 1_{\mathrm{PKC} \gamma}$ to the plasma membrane translates into $I_{\mathrm{Ba}}$ inhibition. This conversion of a normally stimulatory $\mathrm{Ca}_{V} \beta$ 
a

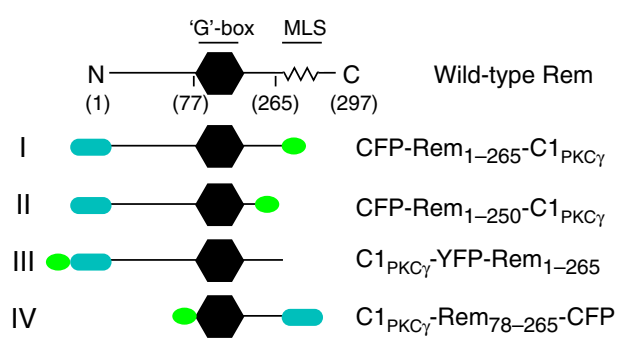

b

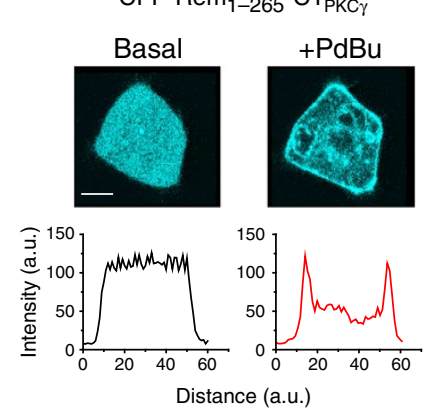

C PM/cytosol ratio

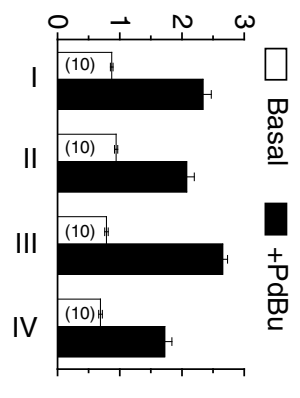

d CFP-Rem $1-265^{-C} 1_{\text {PKC } \gamma}$

e CFP-Rem $_{1-250}-\mathrm{C}_{\mathrm{PKC} \gamma}$

f C1 $1_{\text {PKCY }}{ }^{-Y F P-R e m}{ }_{1-265}$

$\mathbf{g}_{\mathrm{C}_{\mathrm{PKC} \gamma}-\mathrm{Rem}_{78-265} \mathrm{CFP}}$
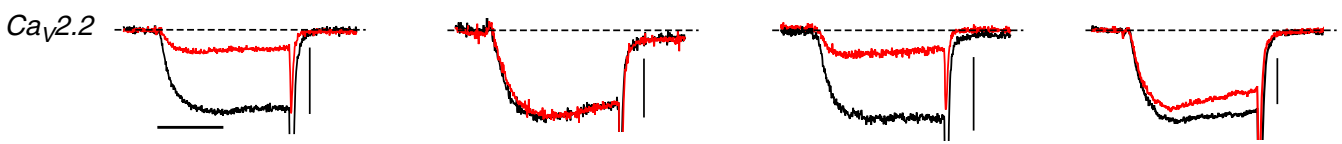

$C a_{V} 2.1$
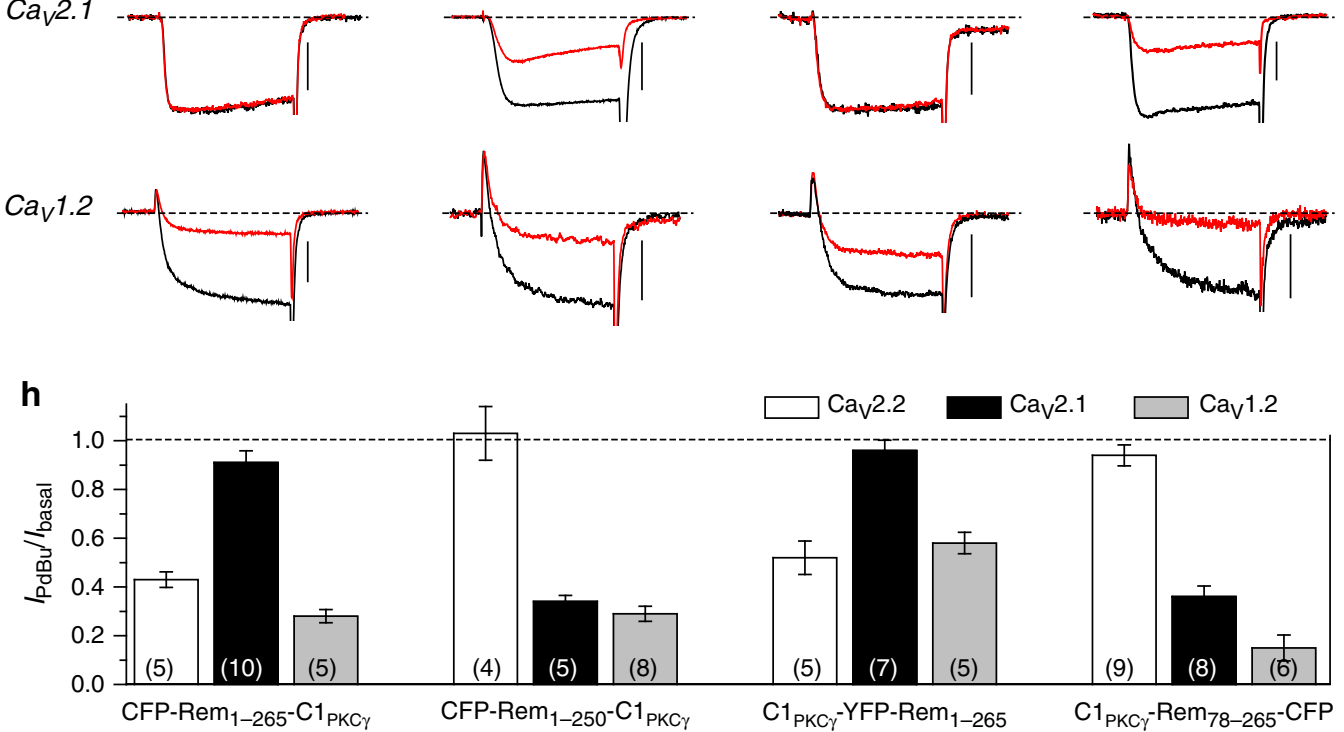

Figure 1 | Placement of membrane-targeting domain influences selectivity and potency of Rem-based Cav1/Cav2 channel blockers. (a) Cartoons of wild-type (wt) Rem and engineered derivatives in which an inducible membrane-targeting $\mathrm{C} 1_{\text {PKC }}$ domain is placed in different positions. Wt Rem contains a guanine nucleotide-binding domain ( $\mathrm{G}$ domain) appended by $\mathrm{N}$ - and $\mathrm{C}$ terminus extensions. The $\mathrm{C}$ terminus contains a polybasic sequence (MLS) that constitutively targets the protein to the plasma membrane. (b) Confocal images (top) and line scan plot (bottom) showing PdBu-induced translocation of CFP-Rem $1-265-{ }^{-} 1_{\text {PKC }}$ from cytosol to the plasma membrane in a transfected HEK 293 cell. Scale bar, $4 \mu \mathrm{m}$. (c) Bar chart showing PdBu-induced increased plasma membrane to cytosol ratio for all four putative Rem-GEMIICCs. (d) Exemplar current waveforms for Cav2.2 (top), Cav2.1 (middle) and Cav1.2 (bottom) channels co-transfected with CFP-Rem $1-265-\mathrm{C1}_{\text {PKC }}$ before (black trace) and shortly after (red trace) exposure to $1 \mu \mathrm{M}$ PdBu. Scale bars, 400 pA, 10 ms. (e-g) Same format as (d), but with cells expressing CFP-Rem $1-250-C 1_{\text {PKC }}, C_{\text {PKC }}$-YFP-Rem $1-265$ and C1 $1_{\text {PKC }}$-Rem $78-265-C F P$, respectively.

(h) Population data showing differential impact of distinct Rem-GEMIICCs on Cav2.2, Cav2.1 and Cav1.2 channels. Data are means \pm s.e.m.

subunit into a CCB provides strong evidence in support of the allosteric pore-closing model we propose for membrane-targeted Rem (Fig. 2a).

$\mathrm{Ca}_{\mathrm{V}} \beta$ s have a conserved core comprised of a $\operatorname{src}$ homology 3 (SH3) and guanylate kinase (GK)-like domains separated by a variable HOOK domain, and flanked by variable-length unstructured $\mathrm{N}$ - and $\mathrm{C}$ termini ${ }^{21-23}$. An $\alpha_{1}$-binding pocket in $\mathrm{Ca}_{\mathrm{V}} \beta \mathrm{GK}$ binds a conserved 18-residue $\alpha_{1}$ interaction domain in the $\alpha_{1}$ subunit I-II loop ${ }^{21-24}$. We hypothesized that placing $\mathrm{C}_{\mathrm{PKC} \gamma}$ closer to GK would result in a more potent, and possibly, kinetically faster $\beta_{3}$-based CCB. This is because the long and presumably floppy $\mathrm{Ca}_{\mathrm{V}} \beta \mathrm{C}$ terminus might be expected to introduce some slackness in the putative PdBu-induced channel conformational change (Fig. 2a). To test this idea we generated a series of constructs in which the relative distance between $\mathrm{C} 1_{\mathrm{PKC} \gamma}$ and GK was systematically varied by serial truncations of the long, unstructured $\beta_{3} C$ terminus (Fig. 2b). The most extreme case featured $\mathrm{Cl}_{\mathrm{PKC} \gamma}$ placed immediately downstream of $\mathrm{GK}$, with no intervening $\beta_{3} \mathrm{C}$ terminus sequence, generating CFP$\beta_{3}\left[\mathrm{C}_{0}\right]-\mathrm{C}_{\mathrm{PKC} \gamma}$. Cells co-expressing $\alpha_{1 \mathrm{~B}}+\mathrm{CFP}-\beta_{3}\left[\mathrm{C}_{0}\right]-\mathrm{C} 1_{\mathrm{PKC} \gamma}$ displayed robust basal $I_{\mathrm{Ba}}$, and exposure to $1 \mu \mathrm{M} \mathrm{PdBu}$ resulted in a strong (80\%), rapid-onset inhibition of current (Fig. 2d). A construct in which $\mathrm{C}_{\mathrm{PKC} \gamma}$ was separated from $\mathrm{GK}$ by 16 residues of the $\mathrm{C}$ terminus, $\mathrm{CFP}-\beta_{3}\left[\mathrm{C}_{16}\right]-\mathrm{C}_{\mathrm{PKC}}$, displayed the deepest $\mathrm{PdBu}$-induced inhibition $(90 \%$ inhibition at $+10 \mathrm{mV}$ test potential), with kinetics of onset intermediate between 
a
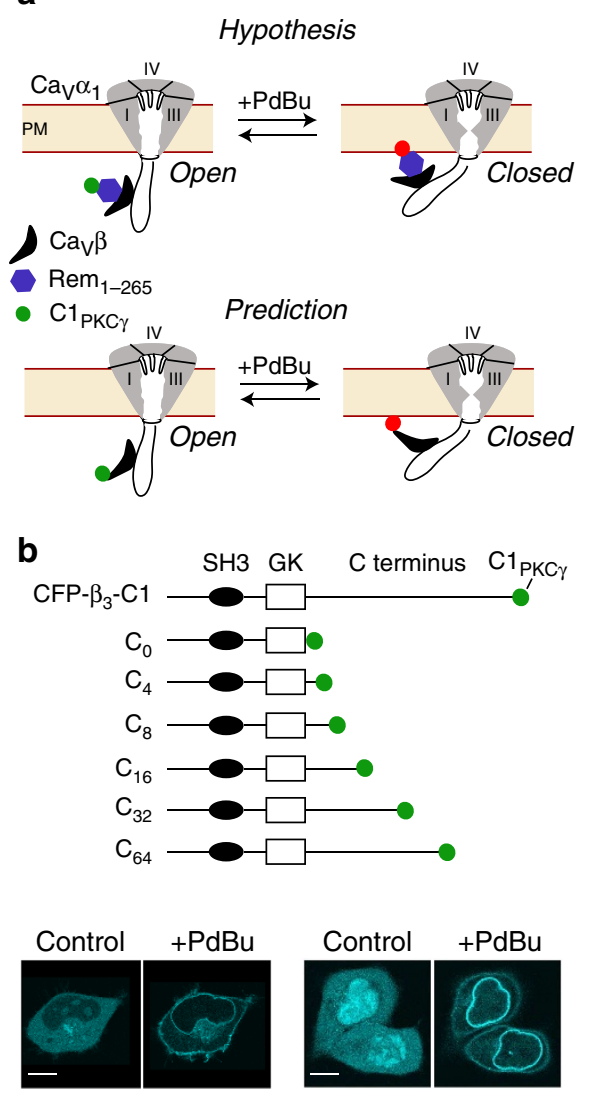

CFP- $\beta_{3}-\mathrm{C} 1$
C

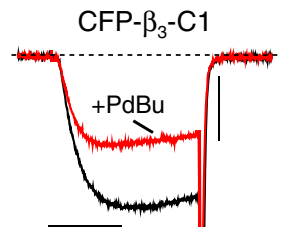

d

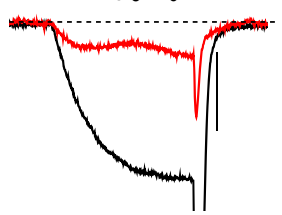

e
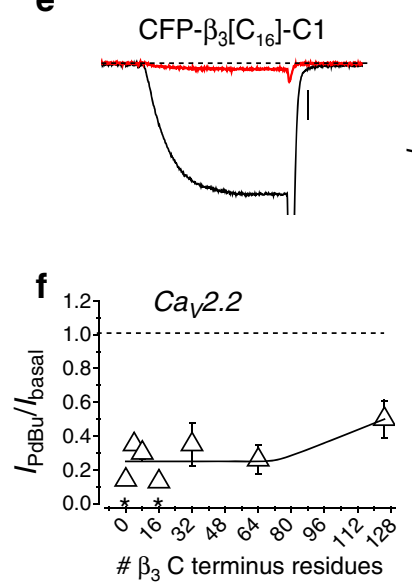
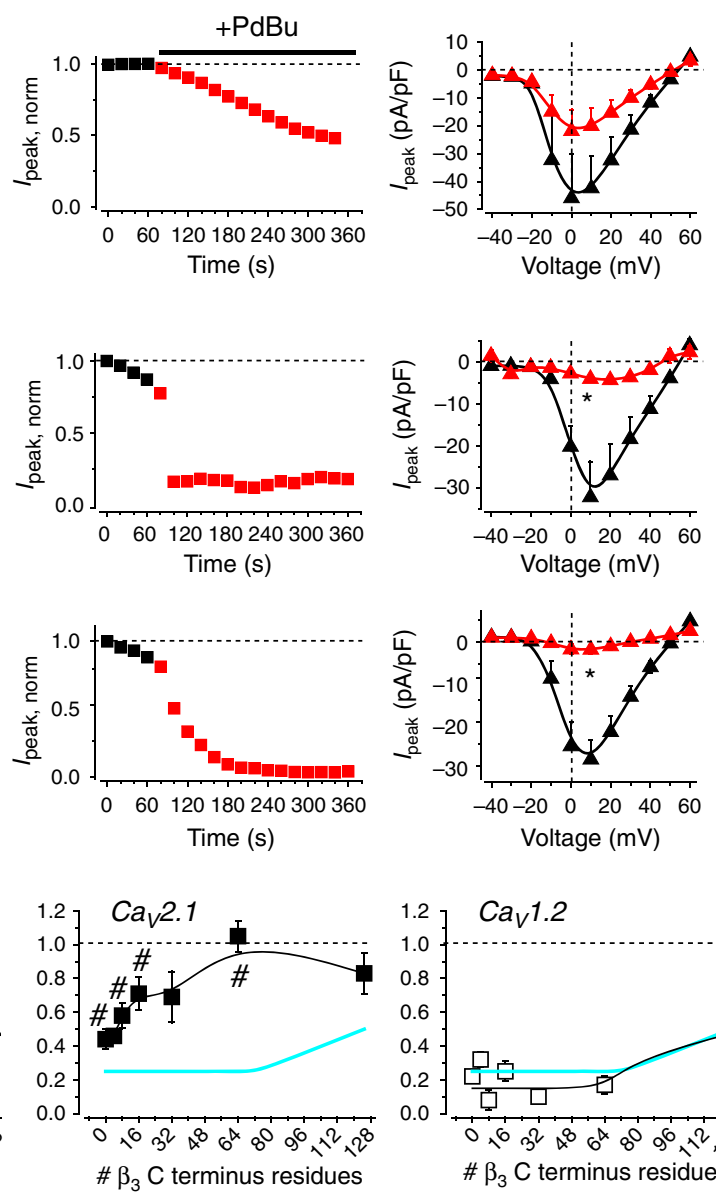

Figure 2 | Design of Cavp-derived CCBs. (a) Top, hypothesis for how the dual requirement for membrane-targeting and Cav $\beta$-binding translates into Rem inhibition of $\mathrm{Ca}_{\vee}$ channels. Bottom, prediction for creating $\beta$-based CCBs. (b) Top, domain arrangement of $\mathrm{Ca}_{V} \beta_{3}$ and sites of $\mathrm{Cl}_{\mathrm{PKC} \gamma}$ placement in the $C$ terminus of serially truncated $\mathrm{Cav}_{\vee} \beta_{3}$ subunits. Bottom, PdBu-induced translocation of CFP- $\beta_{3}-\mathrm{C}_{\mathrm{PKC} \gamma}$ and $\mathrm{CFP}-\beta_{3}\left[\mathrm{C}_{16}\right]-\mathrm{C} 1_{\mathrm{PKC} \gamma}$ from cytosol to plasma membrane. Scale bar, $5 \mu \mathrm{m}$. (c) Left, exemplar currents before (black trace) and after (red trace) exposure to PdBu in HEK 293 cell co-expressing $\mathrm{Ca} 22.2 \alpha_{1 \mathrm{~B}}$ and CFP- $\beta_{3}-\mathrm{C}_{\mathrm{PKC} \gamma}$. Scale bar, $0.5 \mathrm{nA}, 10 \mathrm{~ms}$. Middle, diary plot of $I_{\mathrm{Ba}}$ amplitude before (black squares) and after (red squares) exposure to $1 \mu \mathrm{M}$ PdBu. Right, population I-V curves before (black triangles) and after (red triangles) $1 \mu \mathrm{M} \mathrm{PdBu}$ in cells expressing CFP- $\beta_{3}-\mathrm{C} 1_{\mathrm{PKC}}$. Data are means \pm s.e.m, $n=6$ for each point. (d,e) Data for CFP- $\beta_{3}\left[C_{0}\right]-C 1_{P K C}$ and CFP- $\beta_{3}\left[C_{16}\right]-C 1_{P K C}$, respectively; same format as (c), $n=6$ for each point in $I-V$ plot. ${ }^{\star} P<0.05$ compared with before PdBu data by two-tailed Student's paired $t$-test. (f) Normalized $I_{\mathrm{Ca}}$ inhibition in HEK 293 cells expressing recombinant Cav2.2 (white triangles), Cav2.1 (black squares) or Cav1.2 (white squares) channels reconstituted with the distinct $\beta$-CCBs. Data are means \pm s.e.m, $n=6$ for each point. * significantly different from $C F P-\beta_{3}-C 1_{P K C}$ using one-way ANOVA and Bonferroni test. \#P<0.05 compared with Cav 2.2 data (blue line) by two-tailed Student's paired $t$-test.

$\mathrm{CFP}-\beta_{3}-\mathrm{C}_{\mathrm{PKC} \gamma}$ and $\mathrm{CFP}-\beta_{3}\left[\mathrm{C}_{0}\right]-\mathrm{C}_{\mathrm{PKC} \gamma}$ (Fig. 2e). Population data from experiments using distinct variable-C terminus-length constructs revealed a robust $60-90 \% \mathrm{PdBu}$-induced inhibition of $\mathrm{Ca}_{\mathrm{V}} 2.2$ for $\beta_{3}$-CCBs with $\mathrm{C}$ termini $\leq 64$ residues, some of which were significantly different from the $50 \%$ inhibition seen with full-length $\beta_{3}$ (Fig. $2 \mathrm{f}$, ${ }^{\star} P<0.05$ compared with $\mathrm{CFP}-\beta_{3}-\mathrm{C} 1_{\mathrm{PKC} \gamma}$, by one-way ANOVA and Bonferroni test, $n=6$ for each point). Cells expressing $\alpha_{1 \mathrm{~B}}+$ CFP- $\beta_{3}\left[\mathrm{C}_{16}\right]-\mathrm{C} 1_{\mathrm{PKC}}+\alpha_{2} \delta$ - 1 were similarly inhibited by $\mathrm{PdBu}$, indicating that the $\alpha_{2} \delta-1$ subunit does not prevent this effect (Supplementary Fig. S1). To determine whether this mechanism of inhibition could be generalized to other $\mathrm{Ca}_{\mathrm{V}}$ channels, we also assessed the efficacy of distinct $\beta_{3^{-}}$ CCBs on $\mathrm{Ca}_{\mathrm{V}} 2.1$ and $\mathrm{Ca}_{\mathrm{V}} 1.2$ channels (Fig. 2f, Supplementary Figs S2 and S3). We found that the phenomenon was indeed evident in these other channels-for $\mathrm{Ca}_{\mathrm{V}} 1.2$ the inhibition profile conferred by different $\beta_{3}$-CCBs was similar to $\mathrm{Ca}_{\mathrm{V}} 2.2$ (Fig. $2 \mathrm{f}$, right), whereas $\mathrm{Ca}_{\mathrm{V}} 2.1$ displayed a solid but significantly different inhibition pattern from $\mathrm{Ca}_{\mathrm{V}} 2.2$ (Fig. 2f, middle, $\# P<0.05$ compared with $\mathrm{Ca}_{\mathrm{V}} 2.2$ inhibition, two-tailed unpaired $t$-test, $n=6$ for each point). Regarding the mechanism of inhibition of the $\beta_{3}$-CCBs, we found that PdBu markedly decreased whole-cell current without affecting gating currents (Supplementary Fig. S4). This suggests a selective reduction in either channel $P_{\mathrm{o}}$ or singlechannel conductance, with no change in the number of channels at the cell surface, similar to what we previously found for $\mathrm{PdBu}$ induced Rem-based CCBs ${ }^{18}$.

The effectiveness of membrane-targeted $\beta_{3}$-CCBs in blocking $\mathrm{Ca}_{\mathrm{V}} 1 / \mathrm{Ca}_{\mathrm{V}} 2$ channels was surprising given that two $\mathrm{Ca}_{\mathrm{V}} \beta$ isoforms, $\beta_{2 \mathrm{a}}$ and $\beta_{2 \mathrm{e}}$, natively localize to the plasma membrane via their $\mathrm{N}$ termini, but nevertheless, yield robust $I_{\mathrm{Ba}}$ when reconstituted with $\alpha_{1}$-subunits ${ }^{25,26}$. Moreover, artificially introducing membranetargeting domains to $\mathrm{N}$ termini of cytosolic $\mathrm{Ca}_{\mathrm{V}} \beta$ s does not compromise their ability to reconstitute functional channels with $\alpha_{1}$-subunits ${ }^{27,28}$. One possibility for the discrepancy is that the polarity of the membrane-targeting domain on $\mathrm{Ca}_{\mathrm{V}} \beta$ is important for the impact on channel gating. We examined this idea by placing $\mathrm{Cl}_{\mathrm{PKC} \gamma}$ on $\mathrm{Ca}_{\mathrm{V}} \beta_{3} \mathrm{~N}$ terminus and testing its effectiveness as a CCB. $\mathrm{C}_{\mathrm{PKC}}-\beta_{3}$-CFP reconstituted robust $I_{\mathrm{Ba}}$ 
when co-expressed with $\mathrm{Ca}_{\mathrm{V}} 2.2 \alpha_{1 \mathrm{~B}}$, but exposure to $\mathrm{PdBu}$ had minimal impact on $I_{\mathrm{Ba}}$ (Supplementary Fig. S5), suggesting polarity of the membrane-targeting domain is important for $\beta$-CCB efficacy.

General method for converting $\alpha_{1}$-binding proteins into CCBs. The $\beta_{3}$-CCB results are consistent with a model in which membrane-targeted Rem uses $\mathrm{Ca}_{\mathrm{V}} \beta$ as a 'handle' to alter the conformation of $\alpha_{1}$-subunit I-II loop in a manner that closes the channel pore. As intracellular loops and termini of $\mathrm{Ca}_{\mathrm{v}} 1 / \mathrm{Ca}_{\mathrm{v}} 2$ channels (Fig. 3a) engage in numerous protein-protein interactions, both common and unique, we speculated that other $\alpha_{1}$-binding proteins might be similarly used as 'handles' to manipulate channel gating. If so, this would reveal a generalized principle for designing novel genetically encoded CCBs. To test this premise, we focused on three different proteins (14-3-3, $\mathrm{Ca}^{2+}$-calmodulin-dependent protein kinase II and calmodulin) known to bind intracellular domains of individual $\mathrm{Ca}_{\mathrm{V}} 1 / \mathrm{Ca}_{\mathrm{V}} 2$ channels ${ }^{29-34}$. Wild-type $14-3-3 \varepsilon$ binds $\mathrm{Ca}_{\mathrm{V}} 2.2 \alpha_{1 \mathrm{~B}} \mathrm{C}$ terminus and modulates channel inactivation properties ${ }^{31}$. To determine whether 14-3-3 could be converted into a small-moleculeregulated $\mathrm{Ca}_{\mathrm{V}} 2.2$ inhibitor, we generated $\mathrm{Cl}_{\mathrm{PKC} \gamma}-$ mCherry-14$3-3 \varepsilon$, which is normally cytosolic but rapidly translocates to the plasma membrane with $\mathrm{PdBu}$ (Fig. 3b). Cells co-expressing $\mathrm{Ca}_{\mathrm{V}} 2.2\left(\alpha_{1 \mathrm{~B}}+\beta\right)$ and $\mathrm{Cl}_{\mathrm{PKC}}$-mCherry-14-3-3 displayed robust basal $I_{\mathrm{Ba}}$, and exposure to $1 \mu \mathrm{M}$ PdBu caused a rapid $60 \%$ inhibition of $I_{\mathrm{Ca}}$ amplitude (Fig. 3c). Similar results were obtained with $\mathrm{Ca}_{\mathrm{V}} 2.1$ and $\mathrm{Ca}_{\mathrm{V}} 1.2$, respectively, indicating that these channels also interact with 14-3-3 $\varepsilon$ (Fig. 3c). To our knowledge, it was not previously known that $\mathrm{Ca}_{\mathrm{v}} 1.2$ bound 14-3-3 proteins. Replacing $\mathrm{Cl}_{\mathrm{PKC} \gamma}$ with an 18-residue palmitoylated membranetargeting peptide (mem) from neuromodulin generated memmCherry-14-3-3e, which constitutively targeted to the plasma membrane (Fig. 3d). Remarkably, mem-mCherry-14-3-3E resulted in strong constitutive inhibition of $\mathrm{Ca}_{\mathrm{V}} 2.2, \mathrm{Ca}_{\mathrm{v}} 2.1$ and $\mathrm{Ca}_{\mathrm{V}} 1.2$ channels across all test voltages (Fig. 3e). Control cells expressing mCherry-14-3-3 with $\mathrm{Ca}_{\mathrm{V}} 2.2$ displayed neither inducible nor constitutive $I_{\mathrm{Ba}}$ inhibition (Supplementary Fig. S6).

We next considered whether we could convert $\mathrm{Ca}^{2+}$. calmodulin-dependent protein kinase II (CaMKII) into a CCB. CaMKII has been found to constitutively bind Cav1.2 (ref. 29) and $\mathrm{Ca}_{2} 2.1$ (ref. 30) channels, respectively. CaMKII bound to $\mathrm{Ca}_{\mathrm{V}} 1.2 \mathrm{C}$ terminus was found necessary for $\mathrm{Ca}^{2+}$-dependent facilitation of $I_{\mathrm{Ca}}$ (ref. 29). Further, CaMKII binding to $\mathrm{Ca}_{\mathrm{V}} 2.1 \mathrm{C}$ terminus slows channel inactivation kinetics and regulates shortterm synaptic plasticity in neurons ${ }^{30}$. CaMKII holo-enzyme is a multimer of 12 monomeric subunits ${ }^{35}$. Each monomer (475 amino acids) has three distinct domains: an $\mathrm{N}$-terminal catalytic domain (residues 1-274) that mediates kinase activity, a central regulatory domain (residues 275-314) that exerts basal autoinhibitory control of the kinase domain and an association domain (residues 315-475) that mediates subunit assembly. The catalytic domain of CaMKII mediates binding to $\mathrm{Ca}_{V} 1.2$ channels ${ }^{29}$. To assess the possibility of converting CaMKII into a $\mathrm{CCB}$ we fused either $\mathrm{Cl}_{\mathrm{PKC} \gamma}$ or the polybasic membranetargeting tail from $\mathrm{K}$-Ras to the $\mathrm{C}$ terminus of CaMKII catalytic domain (residues 1-274). We also introduced a K42M point mutation that renders the kinase catalytically $\operatorname{dead}^{35}$. CaMKII ${ }_{[1-274, K 42 \mathrm{M}]}-\mathrm{Cl}_{\mathrm{PKC}}$ inducibly translocated to the membrane (Fig. 3f) and inhibited $\mathrm{Ca}_{\mathrm{v}} 2.2$ and $\mathrm{Ca}_{\mathrm{V}} 1.2$ channels in response to $\mathrm{PdBu}$ (Fig. 3g). Surprisingly, $\mathrm{Ca}_{\mathrm{V}} 2.1$ channels were not inhibited by membrane-translocated $\mathrm{CaMKII}_{[1-274, \mathrm{~K} 42 \mathrm{M}]^{-}}$ $\mathrm{Cl}_{\mathrm{PKC}}$ (Fig. 3g, middle). By contrast, CaMKII ${ }_{[1-274, \mathrm{~K} 42 \mathrm{M}]} \mathrm{KRas}_{\text {tail }}$ was constitutively associated with the plasma membrane (Fig. 3h), and caused a deep inhibition of all three $\mathrm{Ca}_{\mathrm{V}}$ channels
(Fig. 3i). Beyond providing an additional proof of the principle for generating novel genetically encoded CCBs, these results suggest that recombinant $\mathrm{Ca}_{\mathrm{V}} 2.2$ channels may also bind CaMKII. The discrepancy in $\mathrm{Ca}_{\mathrm{v}} 2.1$ sensitivity to $\mathrm{CaMKII}_{[1-274, \mathrm{~K} 42 \mathrm{M}]}-\mathrm{Cl}_{\mathrm{PKC}}$ and $\mathrm{CaMKII}{ }_{[1-274, \mathrm{~K} 42 \mathrm{M}]}-\mathrm{KRas}_{\text {tail }}$ suggests that inhibition by the CaMKII-based inhibitor in this channel may be kinetically slow such that it is only apparent with the constitutive CCB.

Finally, we explored the feasibility of using CaM to create a genetically encoded CCB. CaM is known to bind $\mathrm{Ca}_{\mathrm{V}} 1$ and $\mathrm{Ca}_{\mathrm{V}} 2$ channels and mediates their regulation by $\mathrm{Ca}^{2+}$ ions. We generated mCherry-CaM-C1 $1_{\mathrm{PKC}}$, which displayed basal cytosolic localization but was translocated to the plasma membrane with $\mathrm{PdBu}$ (Fig. 4a). As the endogenous CaM concentration is relatively high, the efficacy of CaM-based CCBs would be expected to depend critically on how effectively they displace endogenous $\mathrm{CaM}$ from the channels. We used $\mathrm{Ca}^{2+}$-dependent inactivation (CDI) of $\mathrm{Ca}_{V} 1.2$ channels as a biosensor to gain insights into how effectively $\mathrm{Cl}_{\mathrm{PKC}}$-tagged wt and mutant $\mathrm{CaM}$ displaced endogenous CaM. When co-expressed with mCherryCaM-C1 $1_{\text {PKC }}$, recombinant $\mathrm{Ca}_{\mathrm{V}} 1.2$ channels $\left(\alpha_{1 \mathrm{C}}+\beta_{2 \mathrm{a}}\right)$ displayed $\mathrm{Ba}^{2+}$ currents that showed a slow monotonic voltage-dependent inactivation (Fig. 4b). With $\mathrm{Ca}^{2+}$ as charge carrier, the same channels exhibited a fast and deep decrease in current amplitude with the kinetic signature of CDI (Fig. 4b). When co-expressed with a mutant mCherry- $\mathrm{CaM}_{1234}-\mathrm{Cl}_{\mathrm{PKC}}$ with all four EF hands mutated so they no longer bind $\mathrm{Ca}^{2+}, \mathrm{Ca}_{\mathrm{V}} 1.2$ channels displayed $\mathrm{Ca}^{2+}$ currents in which CDI was virtually eliminated (Fig. 4b). This result indicates that the over-expressed mCherry- $\mathrm{CaM}_{1234^{-}}$ $\mathrm{Cl}_{\mathrm{PKC}}$ effectively out-competes endogenous $\mathrm{CaM}$ for binding to $C a_{V} 1.2$, and further demonstrates that the tags do not interfere with CaM binding to $\mathrm{Ca}_{\mathrm{V}}$ channels. We found $\mathrm{Ca}_{\mathrm{V}} 2.2$ channels co-expressed with mCherry- $\mathrm{CaM}_{1234}-\mathrm{Cl}_{\mathrm{PKC}}$ were rapidly inhibited by $\mathrm{PdBu}$ (Fig. 4c). Surprisingly, both $\mathrm{Ca}_{\mathrm{v}} 2.1$ and $\mathrm{Ca}_{\mathrm{V}} 1.2$ coexpressed with mCherry-CaM $\mathrm{C}_{1234}-\mathrm{Cl}_{\mathrm{PKC}}$ were unaffected by $\mathrm{PdBu}$ (Fig. 4c). As CaM binds to all three channels ${ }^{32,33,36,37}$, these results suggest that the mere existence of a binding site for a cytosolic protein on the channel may not be sufficient to generate an inducible CCB in all cases. Another possibility is that potential inhibition of $\mathrm{Ca}_{\mathrm{V}} 2.1$ and $\mathrm{Ca}_{\mathrm{V}} 1.2$ induced by membrane-targeting mCherry-CaM ${ }_{1234}-\mathrm{Cl}_{\mathrm{PKC}}$ is kinetically slow such that it does not occur during the 5-10 min time course of our electrophysiological assay.

Overall, these data demonstrate that diverse intracellular proteins interacting with $\mathrm{Ca}_{\mathrm{V}} 1 / \mathrm{Ca}_{\mathrm{V}} 2$ channels can be converted into constitutive or inducible CCBs with distinctive potency and/ or selectivity. We have termed this general method Channel Inactivation induced by Membrane-tethering of an associated Protein (ChIMP). The acronym is apropos given the imagery of closing a channel pore by the induced 'swinging' of an associated protein from the cytoplasm to the plasma membrane (Fig. 2a).

Effectiveness of 14-3-3-based CCB on native $\mathrm{Ca}_{\mathrm{V}}$ channels. The results to this point have tested the efficacy of genetically encoded CCBs on recombinant $\mathrm{Ca}_{\mathrm{V}}$ channels reconstituted in HEK 293 cells. As native $\mathrm{Ca}_{\mathrm{V}}$ channels are typically associated with macromolecular complexes and have a more complicated nanoenviroment than recombinant channels in heterologous cells, it was important to verify that the genetically engineered CCBs were effective against native $\mathrm{Ca}_{\mathrm{V}}$ channels. We first examined the impact of mem-mCherry-14-3-3e on $\mathrm{Ca}_{\mathrm{V}}$ channels recorded from primary cultures of murine dorsal root ganglion (DRG) neurons. DRG neurons express multiple $\mathrm{Ca}_{\mathrm{V}} 1 / \mathrm{Ca}_{\mathrm{V}} 2$ channel currents $^{38}$. We used adenoviral vectors to express either mCherry-14-3-3 or mem-mCherry-14-3-3 (Fig. 5a) in cultured 
a
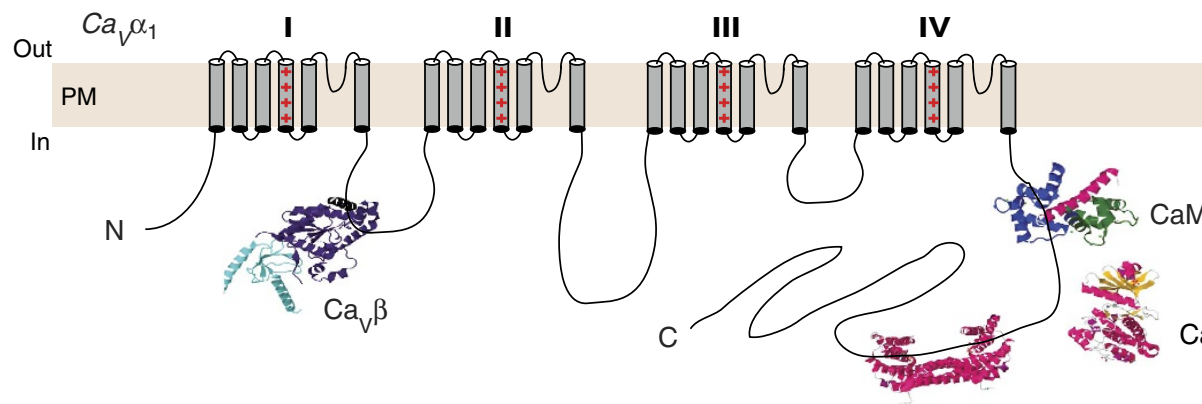

CaMKII

b
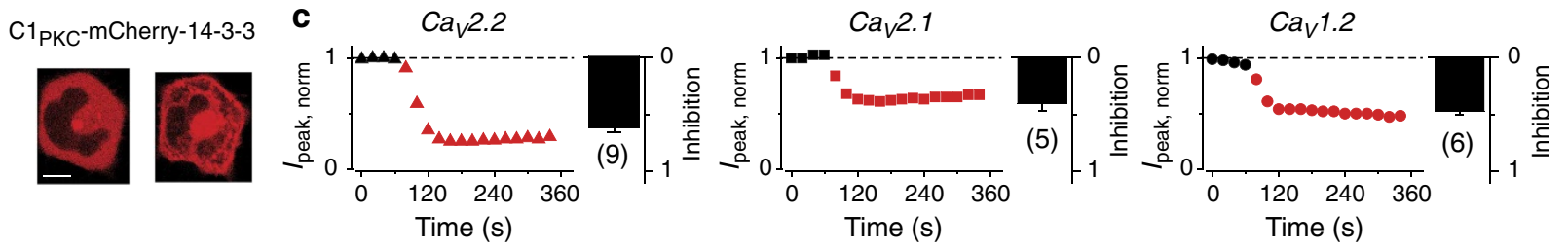

d
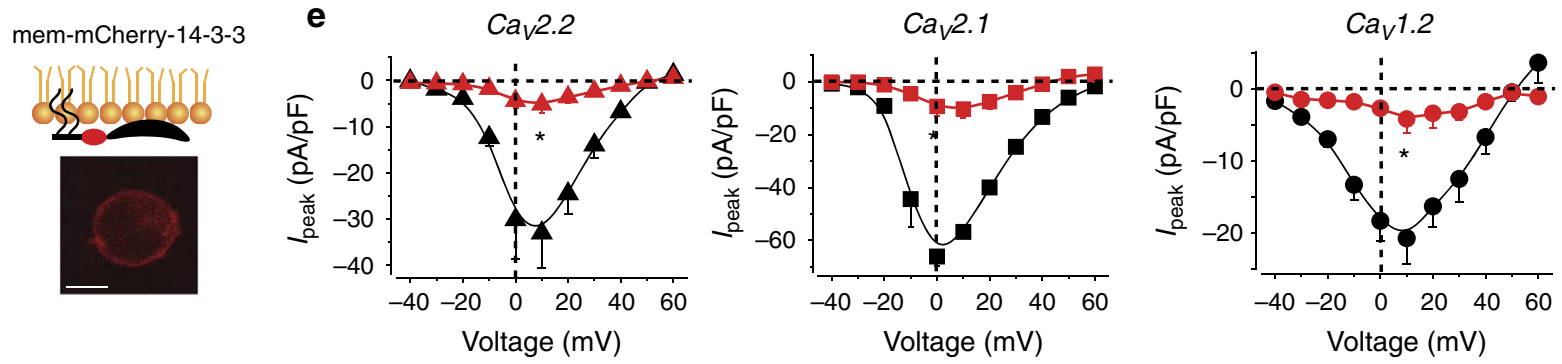

f
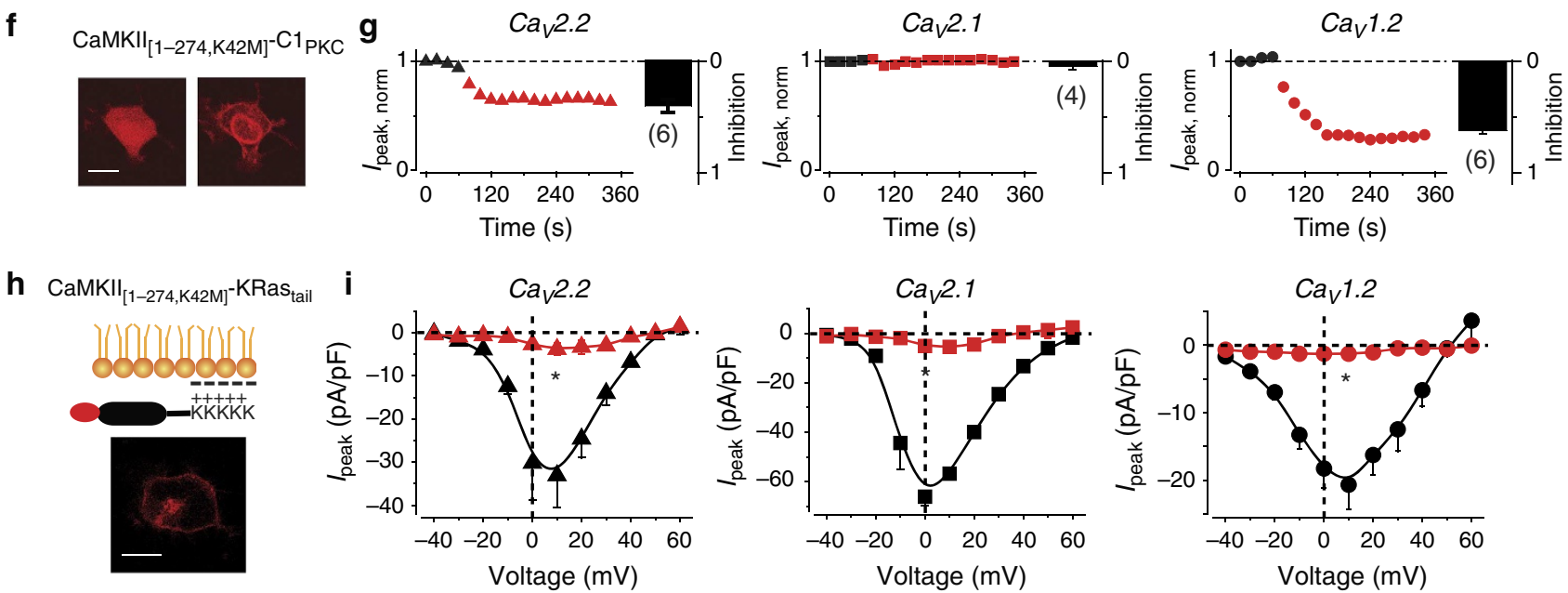

Figure 3 | Generalized method for generating CCBs from $\mathbf{C a}_{\mathbf{v}} \boldsymbol{\alpha}_{\mathbf{1}}$-binding proteins. (a) Schematic of $\mathrm{Ca}_{\vee}$ channel $\alpha_{1}$ subunit. Four homologous domains (I-IV) each with six transmembrane segments are joined by intracellular loops and bracketed by cytoplasmic $\mathrm{N}$ - and $\mathrm{C}$ termini. Various proteins bind $\mathrm{Cav}_{\boldsymbol{V}} \alpha_{1}$ intracellular domains including Cav $\beta, 14-3-3$, CaM kinase II and calmodulin. (b) Confocal images showing PdBu-induced translocation of C1 $1_{\mathrm{PKC}} \gamma^{-}$ mCherry-14-3-3 from the cytosol to the plasma membrane. Scale bar, $4 \mu \mathrm{m}$. (c) Diary plots and population bar charts showing PdBu-induced inhibition of Cav2.2, Cav2.1, and Cav1.2 channels co-expressed with $\mathrm{C}_{\mathrm{PKC}}-$-mCherry-14-3-3. Data are means \pm s.e.m. (d) Schematic and confocal image showing constitutive membrane targeting of mem-mCherry-14-3-3. Scale bar, $5 \mu \mathrm{m}$. (e) Population I-V curves showing constitutive inhibition by mem-mCherry-14-3-3 of $C_{v} 2.2$ (black triangles, red triangles), Cav2.1 (black squares, red squares) and Cav1.2 (black circles, red circles) channels. Data are means \pm s.e.m,

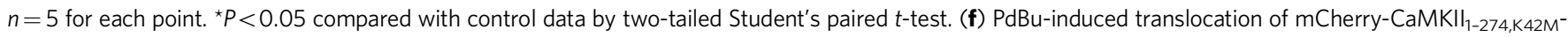
$\mathrm{C}_{\mathrm{PKC}}$ from the cytosol to the plasma membrane. Scale bar, $7 \mu \mathrm{m}$. (g) Diary plots and population bar charts showing PdBu-induced inhibition of Cav2.2, $\mathrm{Ca}_{\mathrm{V}} 2.1$ and Cav1.2 channels co-expressed with mCherry-CaMKIII-274,K42M-C1 $1_{\text {PKC. }}$. Data are means \pm s.e.m. (h) Schematic and confocal image showing constitutive membrane targeting of mCherry-CaMKII $1-274, K 42 \mathrm{M}-\mathrm{KRas}_{\text {tail }}$. Scale bar, $5 \mu \mathrm{m}$. (i) Constitutive inhibition of $\mathrm{Ca}_{V}$ channels by mCherry-CaMKII ${ }_{1-274}$, $\mathrm{K}_{42 \mathrm{M}}-\mathrm{KRas}$ tail. Same format as (c). Data are means \pm s.e.m, $n=5$ for each point. ${ }^{\star} P<0.05$ compared with control data by two-tailed Student's paired $t$-test.

DRG neurons. Cells expressing mCherry-14-3-3 displayed an $I-V$ relationship that was indistinguishable from that obtained with control uninfected neurons (Fig. 5b, left; $I_{\text {peak }}$ at $0 \mathrm{mV}=57.2 \pm 9.9 \mathrm{pA} / \mathrm{pF}, \quad n=6$ for control neurons, $I_{\text {peak }}=62.0 \pm 19.6 \mathrm{pA} / \mathrm{pF}, n=6$ for mCherry-14-3-3-expressing neurons). By contrast, expression of mem-mCherry-14-3-3 $\varepsilon$ in 
a

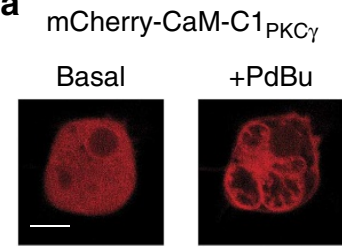

C

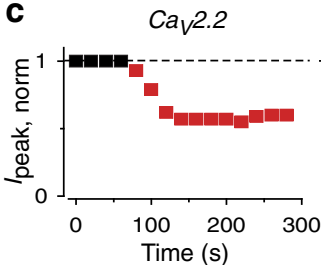

b

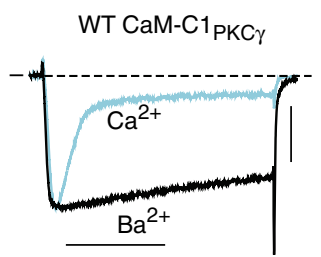

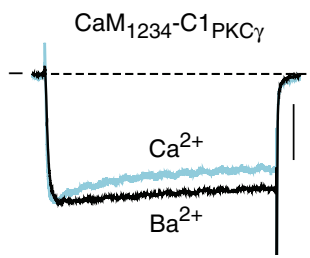

$C a_{V} 2.1$
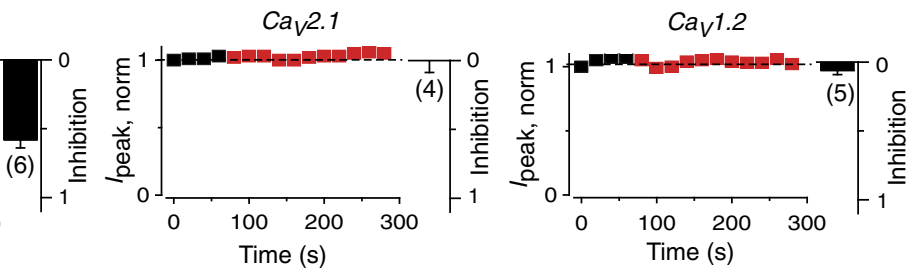

Figure 4 | A CaM-based PdBu-inducible CCB selectively inhibits Cav2.2 channel currents. (a) Confocal image showing PdBu-induced translocation of mCherry-CaM-C1 $1_{\text {PKC }}$ from cytosol to the plasma membrane in a transfected HEK 293 cell. Scale bar, $5 \mu m$. (b) The C1 $1_{\text {PKC }}$ tag does not affect the functional interaction of $\mathrm{CaM}_{\text {or }} \mathrm{CaM}_{1234}$ with $\mathrm{Cav}_{\mathrm{v}} 1.2$. Scale bar, $0.5 \mathrm{nA}, 10 \mathrm{~ms}$. (c) Diary plots and population bar charts showing PdBu-induced effects of

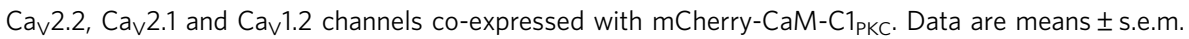

a

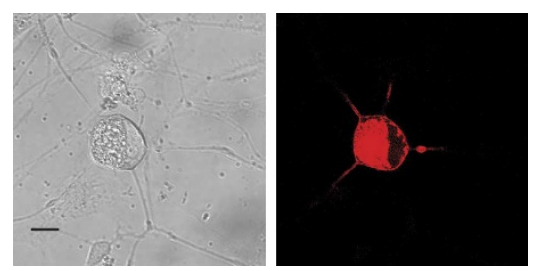

b

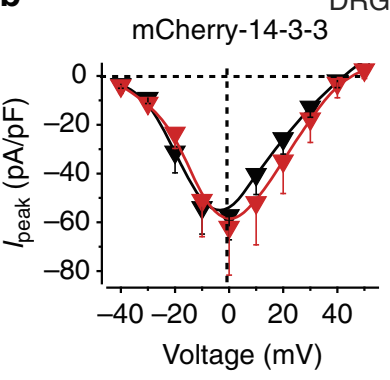

DRG neurons

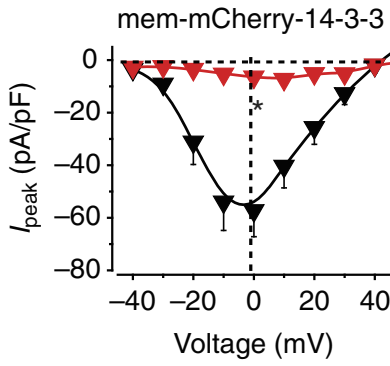

C
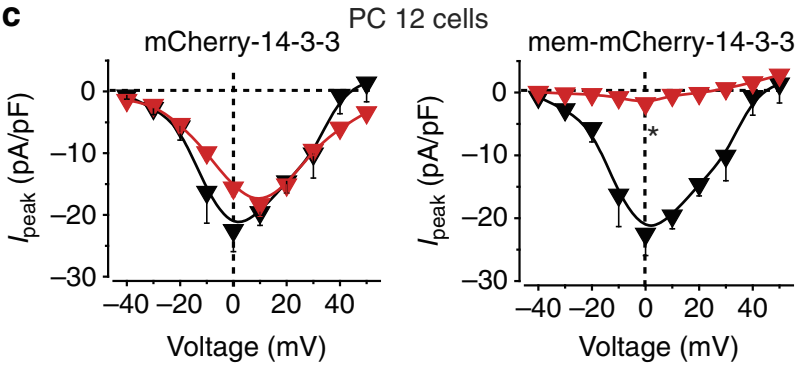

Figure 5 | Constitutive inhibition of endogenous $I_{\mathrm{Ca}}$ in native cells with 14-3-3-based CCBs. (a) Greyscale and fluorescence image of DRG neuron expressing mem-mCherry-14-3-3. Scale bar, $5 \mu \mathrm{m}$. (b) Population I-V curves in DRG neurons. Uninfected neurons (black triangles) compared with neurons expressing either mCherry-14-3-3 (left) or mem-mCherry-143-3 (right), $n=6$ for each point. (c) Population $I-V$ curves in differentiated PC12 cells, same format as (b), $n=5$ for each point. ${ }^{\star} P<0.05$ compared with control data by two-tailed Student's paired $t$-test.

DRG neurons markedly suppressed endogenous $I_{\mathrm{Ba}}$ within $24 \mathrm{~h}$ of adenoviral infection (Fig. $5 \mathrm{~b}$, right; $I_{\text {peak }}=6.3 \pm 1.5 \mathrm{pA} / \mathrm{pF}$, $n=6$ for mem-mCherry-14-3-3-expressing neurons, $P<0.05$ compared with control using unpaired $t$-test). We obtained similar results for nerve growth factor (NGF)-differentiated rat pheochromocytoma (PC12) cells (Fig. 5c), which contain $\mathrm{Ca}_{\mathrm{V}} 2.2$ and $\mathrm{Ca}_{\mathrm{V}} 1.2$ channels that trigger exocytosis ${ }^{39}$. These results demonstrate that genetically engineered CCBs developed according to the ChIMP principle are also effective against native $\mathrm{Ca}_{V} 1 / \mathrm{Ca}_{V} 2$ channels despite their more elaborate nanoenvironment.

Potential use of ChIMP to discover small-molecule CCBs. The results so far suggest the general principle that the discovery process for new CCBs may be decomposed into two parts: first, finding a molecule that binds an appropriate $\alpha_{1}$-subunit cytoplasmic region (a 'handle') and second, a transduction step involving the anchoring of the 'handle' molecule to the plasma membrane. We next considered two ancillary issues. First, whether the 'handle' could be a small molecule rather than a protein as we have so far demonstrated. If so, the ChIMP method could potentially be extended to small-molecule drug discovery. Second, whether it would be possible to develop a method to systematically identify which areas in $\alpha_{1}$ cytoplasmic regions are appropriate target-binding sites that are permissive for regulated closure of the channel pore. To concurrently address these two issues, we adapted a heterodimerization strategy that relies on the ability of the small-molecule rapamycin to simultaneously bind two proteins, FK506-binding protein (FKBP) and a fragment of the mammalian target of rapamycin (FRB), respectively ${ }^{40}$. We inserted FKBP (one insert per channel) at four different positions within $\mathrm{Ca}_{\mathrm{V}} 1.2 \alpha_{1 \mathrm{C}}$ subunit intracellular regions ( $\mathrm{N}$ terminus, I-II loop, and at proximal and distal positions in the $\mathrm{C}$ terminus) (Fig. 6a). All these constructs expressed currents when coexpressed with $\beta_{2 \mathrm{a}}$ and a constitutively membrane-targeted FRB (LDR) in HEK 293 cells $^{18,41}$. Rapamycin $(1 \mu \mathrm{M})$ caused a rapid inhibition of $I_{\mathrm{Ba}}$ in channels with FKBP inserted into the $\mathrm{C}$ terminus (Fig. 6d,e). By contrast, channels with FKBP inserted at the $\mathrm{N}$ terminus and in the distal I-II loop, respectively, did not display rapamycin-induced decrease in current (Fig. 6b,c). Neither of the two $\mathrm{C}$ terminus FKBP-fused channels responded to rapamycin in the absence of LDR (Supplementary Fig. S7). These findings offer a critical proof-of-concept that the ChIMP approach can potentially be used to discover new CCBs by using high-throughput screening to find molecules that bind 

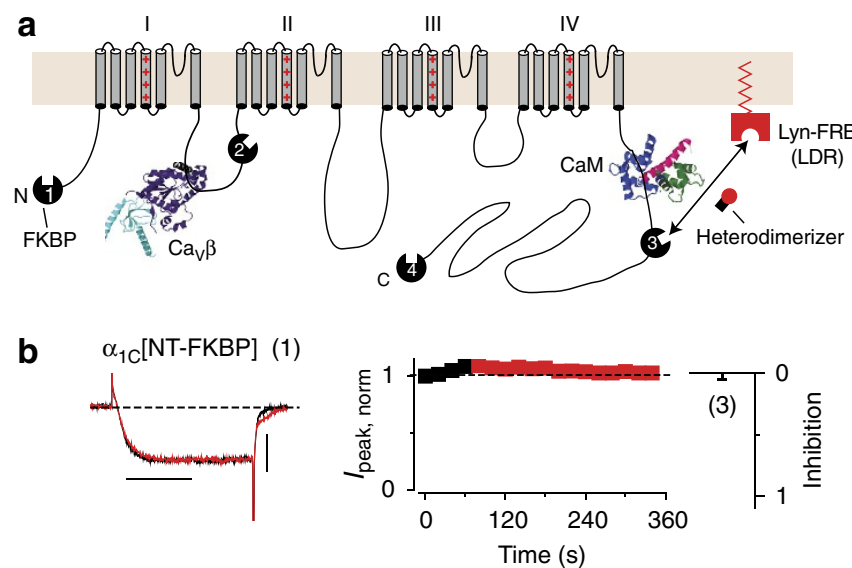

C
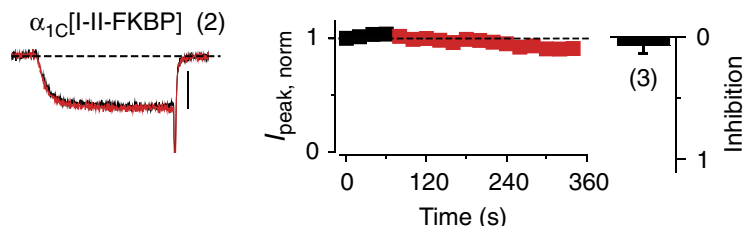

d

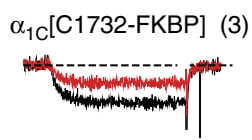

e
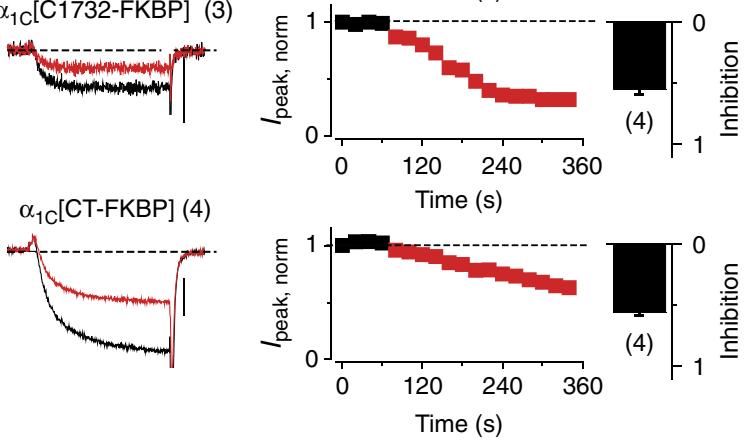

Figure 6 | Principle for developing novel small-molecule CCBs demonstrated using heterodimerization strategy. (a) Insertion of FKBP into selected regions of $\alpha_{1 C}$ intracellular loops/termini. (b-e) Impact of rapamycin on $I_{\mathrm{Ba}}$ from distinct FKBP-fused $\alpha_{1 \mathrm{C}}$ constructs co-transfected with LDR. Scale bar, 400 pA, $10 \mathrm{~ms}$.

appropriate 'handle sites' in $\mathrm{Ca}_{\mathrm{V}} \alpha_{1}$-subunits, and conjugating them to a membrane-targeting module. A major challenge that needs to be overcome to realize this possibility is developing sensitive high-throughput screens to identify small molecules that bind intracellular domains of $\mathrm{Ca}_{\mathrm{V}}$ channels. One possibility is to use purified tagged $\mathrm{Ca}_{\mathrm{V}} \alpha_{1}$ intracellular loops to probe smallmolecule microarrays 42,43 .

\section{Discussion}

In this work we report the discovery that diverse proteins/ molecules that bind distinct sites in intracellular loops of $\mathrm{Ca}_{\mathrm{V}} 1$ / $\mathrm{Ca}_{\mathrm{V}} 2$ channels can be used as 'handles' to inhibit $I_{\mathrm{Ca}}$ through their controlled anchoring to the plasma membrane. This new insight paves the way for developing customized CCBs with selectivity for distinct $\mathrm{Ca}_{V} 1 / \mathrm{Ca}_{V} 2$ channels based on the identity of the pore-forming $\alpha_{1}$-subunit, the auxiliary $\mathrm{Ca}_{V} \beta$ or other associated cytoplasmic proteins. Genetically encoded CCBs are potentially desirable because they can be expressed in a geographically restricted fashion thereby eliminating off-target effects that may confound small-molecule drug therapy ${ }^{2,10}$. Furthermore, genetically encoded CCBs can be engineered to block molecularly identical $\mathrm{Ca}_{\mathrm{V}}$ channels with sub-cellular specificity. For example, a caveolae-targeted Rem has been shown to selectively inhibit caveolae-localized $\mathrm{Ca}_{\mathrm{V}} 1.2$ channels in heart cells while sparing dyadic $\mathrm{Ca}_{V} 1.2$ channels that trigger muscle contraction ${ }^{14}$. As caveolae-localized $\mathrm{Ca}_{\mathrm{V}} 1.2$ channels are hypothesized to selectively signal to pathological cardiac hypertrophy, it is proposed that caveolae-specific $\mathrm{Ca}_{\mathrm{V}} 1.2$ channel inhibitors could be an effective therapy for adverse remodelling of the heart ${ }^{14}$. RGK proteins have so far been used in proof-ofconcept experiments to demonstrate the utility of genetically encoded CCBs ${ }^{10,14}$. However, the potential clinical use of RGKs is complicated by their broad biological effects, diverse binding partners and lack of specificity and controllability ${ }^{11}$. This work introduces ChIMP as a generalized method for developing novel genetically encoded CCBs with distinct potency, selectivity and kinetics. A caveat for the work is that the CCBs we have generated so far are derived from naturally occurring proteins that also have their own specific functions and binding partners in cells. Nevertheless, the general insights obtained from developing these proteins can now be potentially coupled with new technologies for evolving protein molecules that bind to target sites with high specificity, such as DARPins ${ }^{44}$ and intrabodies ${ }^{45}$, to develop highly selective $\mathrm{Ca}_{\mathrm{V}} 1 / \mathrm{Ca}_{\mathrm{V}} 2$ channel blockers. Another aspect of the ChIMP technology that can be greatly improved relates to the method for inducing membrane targeting of the 'handle' protein. Here we used $\mathrm{PdBu}$ and rapamycin-mediated heterodimerization as convenient tools to demonstrate proof-ofconcept of the ChIMP method. However, $\mathrm{PdBu}$ activates endogenous protein kinase $\mathrm{C}$, and rapamycin associates with endogenous FKBP and mammalian target of rapamycin (mTOR), a protein kinase involved in cell proliferation, growth and survival. Hence, these two agents may be inappropriate for potential in vivo applications. Recently, several genetically encoded dimerizers based on plant photoreceptors that permit light-regulated, reversible protein heterodimerization have been developed ${ }^{46-48}$. Marriage of light-regulated heterodimerization with ChIMP could provide a powerful general method for optogenetic control of $\mathrm{Ca}_{\mathrm{V}}$ channels and is an exciting prospect for future experiments.

We previously reported that Rem, which normally constitutively targets to the plasma membrane and inhibits $\mathrm{Ca}_{\mathrm{V}}$ channels, could be converted into a small-molecule-regulated inducible CCB by dynamically regulating its association with the plasma membrane ${ }^{18,19}$. However, it was unknown how targeting Rem to the membrane caused $\mathrm{Ca}_{V}$ channel inhibition. This work supports a model where membrane-targeted Rem uses $\mathrm{Ca}_{\mathrm{V}} \beta$ as a bridge to alter the conformation of the I-II loop in a manner that closes the channel. This is an important new insight into the mechanism of action of RGKs, particularly in light of data that have raised questions about a role for RGK binding to $\mathrm{Ca}_{V} \beta$ in the mechanism for $\mathrm{Ca}_{V}$ channel inhibition ${ }^{49}$. More generally, regulation of channel gating by induced conformational changes in intracellular domains is a rather common phenomenon that occurs in many different ion channels. For example, cyclic nucleotides and $\mathrm{Ca}^{2+}$ control the opening of cyclic nucleotidegated (CNG) and large conductance $\mathrm{K}^{+}$(BK) channels, respectively, by binding to channel intracellular domains ${ }^{50,51}$. Moreover, engagement of cytoplamic domains with the plasma membrane through interaction with phosphoinositide lipids regulates the gating of ion channels such as the inward rectifier $\mathrm{K}^{+}$channel Kir2.2 (ref. 52) and TRPV1 (ref. 53). From this perspective, the ChIMP approach could provide important insights into how distinct intracellular domains link to channel gating in different ion channels.

The major conceptual advance in this study is that diverse cytosolic proteins or small molecules that bind distinct sites in intracellular loops of $\mathrm{Ca}_{\mathrm{V}} 1 / \mathrm{Ca}_{\mathrm{V}} 2$ channels can likewise be converted to constitutive or inducible $\mathrm{Ca}_{\mathrm{V}}$ channel inhibitors 
according to the mode of their anchoring to the plasma membrane. This is a non-trivial advance because it suggests a general method for developing novel genetically encoded blockers for many ion channel types. Ion channels are ubiquitous and essential to the biology of all cell types, and their dysfunction underlies many human diseases ${ }^{54}$. Selective ion channel modulators are highly sought after as therapeutics and research tools. However, there is a lack of specific modulators for many ion channel species. The ChIMP strategy may potentially be applied to develop novel blockers for a broad cohort of ion channels.

A corollary benefit of the ChIMP approach is its potential to provide a robust functional readout as to whether individual proteins directly interact with intracellular domains of recombinant $\mathrm{Ca}_{\mathrm{v}} 1 / \mathrm{Ca}_{\mathrm{v}} 2$ channels. In our study, we discovered for the first time that recombinant $\mathrm{Ca}_{\mathrm{v}} 1.2$ binds 14-3-3 and that $\mathrm{Ca}_{\mathrm{V}} 2.2$ binds CaMKII. A proteomic study of the $\mathrm{Ca}_{\mathrm{v}} 2$ channel nanoenvironment in mammalian brain indicates these channels are associated with a protein network gathered from a pool of $\sim 200$ proteins with distinct abundance and preference for $\mathrm{Ca}_{\mathrm{V}} 2.1-\mathrm{Ca}_{\mathrm{V}} 2.3$ subtypes $^{55}$. Our studies suggest how $\mathrm{Ca}_{\mathrm{V}} 1 / \mathrm{Ca}_{\mathrm{V}} 2$ channels may be used as a biosensor to validate some of these putative protein interactions.

\section{Methods}

cDNA cloning. To generate fluorescent-protein-tagged constructs, cyan or yellow fluorescent protein (CFP or YFP) was amplified using PCR and cloned into pcDNA4.1 (Invitrogen) using KpnI and BamHI sites. CFP-Rem ${ }_{1-265}-\mathrm{Cl}_{\mathrm{PKC} \gamma}$ and CFP-Rem $1-250-\mathrm{Cl}_{\mathrm{PKC} \gamma}$ were generated by using overlap extension PCR to fuse residues 26-89 of mouse PKC $\gamma$ to the $C$ terminus of $\operatorname{Rem}_{1-265}$ and $\operatorname{Rem}_{1-250}$, respectively. The fusion product was subsequently cloned downstream of CFP using BamHI and EcoRI sites. To create $\mathrm{C}_{\mathrm{PKC} \gamma}-\mathrm{Rem}_{78-265}-\mathrm{CFP}, \mathrm{C} 1_{\mathrm{PKC} \gamma}$ was cloned into pcDNA4.1 (Invitrogen) using KpnI and BamHI sites. Rem ${ }_{78-265}$ and CFP were subsequently amplified and cloned downstream of $\mathrm{C}_{\mathrm{PKC} \gamma}$ using BamHI/EcoRI and EcoRI/XbaI sites, respectively. $\mathrm{C1}_{\mathrm{PKC} \gamma}$-YFP-Rem ${ }_{1-265}$ was produced by first using overlap extension PCR to fuse $\mathrm{C}_{\mathrm{PKC} \gamma}$ to the $\mathrm{N}$ terminus of YFP. The resulting fusion product was cloned upstream of $\mathrm{Rem}_{1-265}$ using KpnI and $\mathrm{BamHI}$ sites. CFP- $\beta_{3}-\mathrm{C} 1_{\mathrm{PKC} \gamma}$ was generated by using overlap extension PCR to fuse $\mathrm{Cl}_{\mathrm{PKC} \gamma}$ to the $\mathrm{C}$ terminus of $\beta_{3}$. The fusion product was then cloned downstream of CFP using BamHI and EcoRI sites. To generate $\mathrm{Cl}_{\mathrm{PKC} \gamma}$-mcherry14-3-3, we used overlap extension PCR to fuse $\mathrm{C} 1_{\mathrm{PKC} \gamma}$ to the $\mathrm{N}$ terminus of mCherry. The fusion product was cloned into pcDNA4.1 (Invitrogen) using KpnI and $\mathrm{BamHI}$ sites. 14-3-3 was PCR amplified and cloned downstream of mcherry using BamHI and XhoI sites. To create mcherry-CaMKII $1-274 \mathrm{~K}_{22} \mathrm{M}^{-} \mathrm{Cl}_{\mathrm{PKC} \gamma}$, we used overlap extension PCR to fuse $\mathrm{C}_{\mathrm{PKC} \gamma}$ to the $\mathrm{C}$ terminus of $\mathrm{CaMKII}_{1-274}$. The fusion product was cloned into pcDNA4.1 (Invitrogen) using BamHI and XhoI sites sites. mcherry was PCR-amplified and cloned upstream using KpnI and

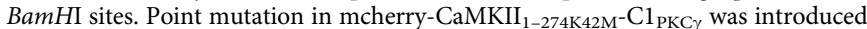
using the QuikChange Site-Directed Mutagenesis Kit (Stratagene). To generate FKBP-fused $\alpha_{1 C}$ constructs, we used overlap extension PCR to fuse YFP to the C terminus of $\alpha_{1 \mathrm{C}}$. The fusion product was cloned into pcDNA3.1 (Invitrogen) using KpnI and $\mathrm{XbaI}$ sites. FKBP was inserted into distinct regions of $\alpha_{1 \mathrm{C}}$ intracellular loops using In-fusion Cloning Kit (Clontech). All PCR products were verified by sequencing.

Cell culture and transfection. Low-passage-number HEK 293 cells were maintained in DMEM supplemented with $10 \%$ FBS and $100 \mu \mathrm{g} \mathrm{ml}^{-1}$ penicillinstreptomycin. For electrophysiology and flow cytometry experiments, HEK 293 cells cultured in $6-\mathrm{cm}$ tissue culture dishes were transiently transfected with $\mathrm{Ca}_{V} 1 / \mathrm{Ca}_{\mathrm{V}} 2 \alpha_{1}(6 \mu \mathrm{g}), \beta_{3}(6 \mu \mathrm{g})$, T antigen $(2 \mu \mathrm{g})$ and the appropriate GEMIICC construct $(4 \mu \mathrm{g})$, using the calcium phosphate precipitation method. Cells were washed with PBS 5-8 h after transfection and maintained in supplemented DMEM. For confocal microscopy experiments, transfected HEK 293 cells were replated onto fibronectin-coated culture dishes with No. 0 glass coverslip bottoms (MaTek). For electrophysiology experiments cells were replated onto fibronectin-coated glass coverslips $24 \mathrm{~h}$ after transfection.

Murine dorsal root ganglion (DRG) neurons were kindly provided by the laboratory of Dr Joachim Scholz (Columbia University). DRG neurons were maintained in $96.5 \mathrm{ml}$ Neurobasal A medium supplemented with $2 \mathrm{ml} \mathrm{B-27}$,

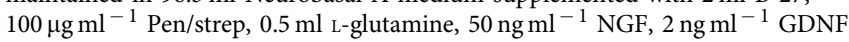
and $10 \mu \mathrm{M}$ Ara-C. For electrophysiology experiments, DRG neurons cultured in $2-\mathrm{cm}$ tissue culture dishes were infected with the appropriate adenovirus. Undifferentiated PC12 cells were maintained in RPMI supplemented with $10 \%$ horse serum, 5\% FBS and $100 \mathrm{\mu g} \mathrm{ml}^{-1}$ penicillin-streptomycin. Differentiated PC12 cells were maintained in RPMI supplemented with $1 \%$ horse serum. NGF $\left(50 \mathrm{ng} \mathrm{ml}^{-1}\right)$ was added to media just prior to use. For electrophysiology experiments, PC12 cells cultured in 6-cm tissue culture dishes were infected with the appropriate adenovirus.

Electrophysiology. Whole-cell recordings of HEK cells were conducted $48-72 \mathrm{~h}$ after transfection using an EPC-8 or EPC-10 patch clamp amplifier (HEKA Electronics) controlled by PULSE software (HEKA). Micropipettes were fashioned from 1.5-mm thin-walled glass with filament (WPI Instruments) and filled with internal solution containing (in $\mathrm{mM}$ ): 135 caesium methanesulphonate $\left(\mathrm{CsMeSO}_{3}\right), 5$ CsCl, 5 EGTA, $1 \mathrm{MgCl}_{2}$, $4 \mathrm{MgATP}$ (added fresh) and $10 \mathrm{HEPES}$ (pH 7.3). Series resistance was typically between $1.5-2 \mathrm{M} \Omega$. There was no electronic series resistance compensation. External solution contained (in $\mathrm{mM}$ ): 140 tetraethylammonium- $\mathrm{MeSO}_{3}, 5 \mathrm{BaCl}_{2}$, and $10 \mathrm{HEPES}$ ( $\mathrm{pH} 7.3$ ). Whole-cell $I-V$ curves were generated from a family of step depolarizations $(-40$ to $+100 \mathrm{mV}$ from a holding potential of $-90 \mathrm{mV}$ ). Currents were sampled at $25 \mathrm{kHz}$ and filtered at 5 or $10 \mathrm{kHz}$. Traces were acquired at a repetition interval of $6 \mathrm{~s}$. Leak and capacitive currents were subtracted using a $\mathrm{P} / 8$ protocol.

Whole-cell recordings of DRG and PC12 cells were conducted 24-48 h after infection. HEK cell internal solution was used for both DRG and PC12 cells. HEK cell external solution was used for PC12 cells. HEK cell external solution with $0.5 \mu \mathrm{M}$ TTX was used for DRG neurons.

Confocal microscopy. Static images of CFP-Rem ${ }_{1-265}-\mathrm{Cl}_{\mathrm{PKC} \gamma}, \mathrm{CFP}-\beta_{3}-\mathrm{Cl}_{\mathrm{PKC} \gamma}$, and mcherry-C1 $1_{\mathrm{PKC} \gamma}-14-3-3$ constructs were observed using a Leica TCS SPL AOBS MP Confocal microscope system and a $\times 40$ oil objective (HCX PL APO 1.25-0.75 NA). HEK 293 cells expressing CFP, YFP and mCherry fusion proteins were imaged using the 458-, 514- and 543-nm Argon laser line, respectively, for excitation.

Data and statistical analyses. Data were analysed off-line using PulseFit (HEKA), Microsoft Excel and Origin software. Statistical analyses were performed in Origin using built-in functions. Statistically significant differences between means $(P<0.05)$ were determined using Student's $t$-test for comparisons between two groups or one-way ANOVA followed by pairwise means comparisons using Bonferroni test for multiple groups. Data are presented as means \pm s.e.m.

\section{References}

1. Catterall, W. A. Structure and regulation of voltage-gated $\mathrm{Ca} 2+$ channels. Annu. Rev. Cell Dev. Biol. 16, 521-555 (2000).

2. $\mathrm{Xu}, \mathrm{X} . \&$ Colecraft, H. M. Engineering proteins for custom inhibition of $\mathrm{Ca}(\mathrm{V})$ channels. Physiology (Bethesda) 24, 210-218 (2009).

3. Anekonda, T. S. \& Quinn, J. F. Calcium channel blocking as a therapeutic strategy for Alzheimer's disease: the case for isradipine. Biochim. Biophys. Acta 1812, 1584-1590 2011.

4. Kochegarov, A. A. Pharmacological modulators of voltage-gated calcium channels and their therapeutical application. Cell Calcium 33, 145-162 (2003)

5. Simuni, T. et al. Tolerability of isradipine in early Parkinson's disease: a pilot dose escalation study. Mov. Disord. 25, 2863-2866 (2010).

6. Triggle, D. J. Calcium channel antagonists: clinical uses-past, present and future. Biochem. Pharmacol. 74, 1-9 (2007).

7. Striessnig, J. et al. Structural basis of drug binding to $\mathrm{L} \mathrm{Ca} 2+$ channels. Trends Pharmacol. Sci. 19, 108-115 (1998).

8. Uchitel, O. D. Toxins affecting calcium channels in neurons. Toxicon 35, 1161-1191 (1997).

9. Zuccotti, A. et al. Structural and functional differences between L-type calcium channels: crucial issues for future selective targeting. Trends Pharmacol. Sci. 32, 366-375 (2011).

10. Murata, M., Cingolani, E., McDonald, A. D., Donahue, J. K. \& Marban, E. Creation of a genetic calcium channel blocker by targeted gem gene transfer in the heart. Circ. Res. 95, 398-405 (2004).

11. Yang, T. \& Colecraft, H. M. Regulation of voltage-dependent calcium channels by RGK proteins. Biochim. Biophys. Acta 1828, 1644-1654 2012.

12. Beguin, P. et al. Regulation of $\mathrm{Ca} 2+$ channel expression at the cell surface by the small G-protein kir/Gem. Nature 411, 701-706 (2001).

13. Finlin, B. S., Crump, S. M., Satin, J. \& Andres, D. A. Regulation of voltage-gated calcium channel activity by the Rem and Rad GTPases. Proc. Natl Acad. Sci. USA 100, 14469-14474 (2003).

14. Makarewich, C. A. et al. A caveolae-targeted L-type $\mathrm{Ca}(2)+$ channel antagonist inhibits hypertrophic signaling without reducing cardiac contractility. Circ. Res. 110, 669-674 (2012).

15. Correll, R. N., Pang, C., Niedowicz, D. M., Finlin, B. S. \& Andres, D. A. The RGK family of GTP-binding proteins: regulators of voltage-dependent calcium channels and cytoskeleton remodeling. Cell Signal. 20, 292-300 (2008).

16. Flynn, R. \& Zamponi, G. W. Regulation of calcium channels by RGK proteins Channels (Austin) 4, 434-439 (2010).

17. Yang, T., Puckerin, A. \& Colecraft, H. M. Distinct RGK GTPases differentially Use alpha(1)- and auxiliary beta-binding-dependent mechanisms to inhibit $\mathrm{Ca}(\mathrm{V}) 1.2 / \mathrm{Ca}(\mathrm{V}) 2.2$ channels. PLoS One 7, e37079 (2012). 
18. Yang, T., Suhail, Y., Dalton, S., Kernan, T. \& Colecraft, H. M. Genetically encoded molecules for inducibly inactivating CaV channels. Nat. Chem. Biol. 3, 795-804 (2007).

19. Yang, T., Xu, X., Kernan, T., Wu, V. \& Colecraft, H. M. Rem, a member of the RGK GTPases, inhibits recombinant CaV1.2 channels using multiple mechanisms that require distinct conformations of the GTPase. J. Physiol. 588, 1665-1681 (2010).

20. Buraei, Z. \& Yang, J. The $\{$ beta $\}$ subunit of voltage-gated Ca2 + channels. Physiol. Rev. 90, 1461-1506 (2010).

21. Chen, Y. H. et al. Structural basis of the alpha1-beta subunit interaction of voltage-gated Ca2 + channels. Nature 429, 675-680 (2004).

22. Opatowsky, Y., Chen, C. C., Campbell, K. P. \& Hirsch, J. A. Structural analysis of the voltage-dependent calcium channel beta subunit functional core and its complex with the alpha 1 interaction domain. Neuron 42, 387-399 (2004).

23. Van Petegem, F., Clark, K. A., Chatelain, F. C. \& Minor, Jr. D. L. Structure of a complex between a voltage-gated calcium channel beta-subunit and an alphasubunit domain. Nature 429, 671-675 (2004).

24. Pragnell, M. et al. Calcium channel beta-subunit binds to a conserved motif in the I-II cytoplasmic linker of the alpha 1-subunit. Nature 368, 67-70 (1994).

25. Takahashi, S. X., Mittman, S. \& Colecraft, H. M. Distinctive modulatory effects of five human auxiliary beta 2 subunit splice variants on L-type calcium channel gating. Biophys. J. 84, 3007-3021 (2003).

26. Chien, A. J. et al. Roles of a membrane-localized beta subunit in the formation and targeting of functional L-type Ca2 + channels. J Biol Chem 270, 30036-30044 (1995)

27. Restituito, S. et al. The [beta]2a subunit is a molecular groom for the $\mathrm{Ca} 2+$ channel inactivation gate. J. Neurosci. 20, 9046-9052 (2000).

28. Suh, B. C., Kim, D. I., Falkenburger, B. H. \& Hille, B. Membrane-localized betasubunits alter the PIP2 regulation of high-voltage activated $\mathrm{Ca} 2+$ channels. Proc. Natl Acad. Sci. USA 109, 3161-3166 (2012)

29. Hudmon, A. et al. CaMKII tethers to L-type Ca2 + channels, establishing a local and dedicated integrator of $\mathrm{Ca} 2+$ signals for facilitation. J. Cell Biol. 171, 537-547 (2005).

30. Jiang, X. et al. Modulation of CaV2.1 channels by Ca2 +/calmodulindependent protein kinase II bound to the C-terminal domain. Proc. Natl Acad. Sci. USA 105, 341-346 (2008).

31. Li, Y., Wu, Y. \& Zhou, Y. Modulation of inactivation properties of CaV2.2 channels by 14-3-3 proteins. Neuron 51, 755-771 (2006).

32. Peterson, B. Z., DeMaria, C. D., Adelman, J. P. \& Yue, D. T. Calmodulin is the $\mathrm{Ca} 2+$ sensor for $\mathrm{Ca} 2+$-dependent inactivation of L-type calcium channels. Neuron 22, 549-558 (1999).

33. Lee, A. et al. $\mathrm{Ca} 2+/$ calmodulin binds to and modulates P/Q-type calcium channels. Nature 399, 155-159 (1999).

34. Zuhlke, R. D., Pitt, G. S., Deisseroth, K., Tsien, R. W. \& Reuter, H. Calmodulin supports both inactivation and facilitation of L-type calcium channels. Nature 399, 159-162 (1999).

35. Chao, L. H. et al. A mechanism for tunable autoinhibition in the structure of a human Ca2 + /calmodulin- dependent kinase II holoenzyme. Cell 146, 732-745 (2011).

36. Liang, H. et al. Unified mechanisms of $\mathrm{Ca} 2+$ regulation across the $\mathrm{Ca} 2+$ channel family. Neuron 39, 951-960 (2003).

37. Van Petegem, F., Chatelain, F. C. \& Minor, Jr. D. L. Insights into voltage-gated calcium channel regulation from the structure of the CaV1.2 IQ domain$\mathrm{Ca} 2+/$ calmodulin complex. Nat. Struct. Mol. Biol. 12, 1108-1115 (2005).

38. Scroggs, R. S. \& Fox, A. P. Multiple Ca2 + currents elicited by action potential waveforms in acutely isolated adult rat dorsal root ganglion neurons. J. Neurosci. 12, 1789-1801 (1992).

39. Taylor, S. C. \& Peers, C. Store-operated Ca2 + influx and voltage-gated $\mathrm{Ca} 2+$ channels coupled to exocytosis in pheochromocytoma (PC12) cells. J. Neurochem. 73, 874-880 (1999).

40. Crabtree, G. R. \& Schreiber, S. L. Three-part inventions: intracellular signaling and induced proximity. Trends Biochem. Sci. 21, 418-422 (1996).

41. Inoue, T., Heo, W. D., Grimley, J. S., Wandless, T. J. \& Meyer, T. An inducible translocation strategy to rapidly activate and inhibit small GTPase signaling pathways. Nat. Methods 2, 415-418 (2005).

42. Bradner, J. E. et al. A robust small-molecule microarray platform for screening cell lysates. Chem. Biol. 13, 493-504 (2006).
43. Noblin, D. J. et al. A HaloTag-based small molecule microarray screening methodology with increased sensitivity and multiplex capabilities. ACS Chem. Biol. 7, 2055-2063 (2012).

44. Boersma, Y. L. \& Pluckthun, A. DARPins and other repeat protein scaffolds: advances in engineering and applications. Curr. Opin. Biotechnol. 22, 849-857 (2011).

45. Zhou, C. \& Przedborski, S. Intrabody and Parkinson's disease. Biochim. Biophys. Acta 1792, 634-642 (2009).

46. Kennedy, M. J. et al. Rapid blue-light-mediated induction of protein interactions in living cells. Nat. Methods 7, 973-975 (2010).

47. Levskaya, A., Weiner, O. D., Lim, W. A. \& Voigt, C. A. Spatiotemporal contro of cell signalling using a light-switchable protein interaction. Nature 461, 997-1001 (2009)

48. Yazawa, M., Sadaghiani, A. M., Hsueh, B. \& Dolmetsch, R. E. Induction of protein-protein interactions in live cells using light. Nat. Biotechnol. 27, 941-945 (2009).

49. Fan, M., Buraei, Z., Luo, H. R., Levenson-Palmer, R. \& Yang, J. Direct inhibition of P/Q-type voltage-gated $\mathrm{Ca} 2+$ channels by Gem does not require a direct Gem/Cavbeta interaction. Proc. Natl Acad. Sci. USA 107, 14887-14892 (2010).

50. Craven, K. B. \& Zagotta, W. N. CNG and HCN channels: two peas, one pod. Annu. Rev. Physiol. 68, 375-401 (2006).

51. Salkoff, L., Butler, A., Ferreira, G., Santi, C. \& Wei, A. High-conductance potassium channels of the SLO family. Nat. Rev. Neurosci. 7, 921-931 (2006).

52. Hansen, S. B., Tao, X. \& MacKinnon, R. Structural basis of PIP2 activation of the classical inward rectifier K + channel Kir2.2. Nature 477, 495-498 (2011).

53. Cao, E., Cordero-Morales, J. F., Liu, B., Qin, F. \& Julius, D. TRPV1 channels are intrinsically heat sensitive and negatively regulated by phosphoinositide lipids. Neuron 77, 667-679 (2013).

54. Ashcroft, F. M. Ion Channels and Disease (Academic Press, 1999).

55. Muller, C. S. et al. Quantitative proteomics of the Cav2 channel nanoenvironments in the mammalian brain. Proc. Natl Acad. Sci. USA 107, 14950-14957 (2010).

\section{Acknowledgements}

We thank Drs T. Meyer (Stanford University) and T. Inoue (Johns Hopkins University) for FRB construct (LDR), Drs Ademuyiwa Aromolaran and Prakash Subramanyam for comments on the manuscript, Dr David Yue (Johns Hopkins University) for discussions, Drs Llloyd Greene and Oren Levy (Columbia University) for PC12 cells, Dr Joachim Scholz (Columbia University) for DRG neurons, and Brian Soda for assistance with the ChIMP illustration artwork. This work was supported by NIH grants RO1 HL084332 and RO1 HL069911 (to H.M.C). L.L.H. was supported by a NIH postdoctoral training grant (T32 HL087745). H.M.C. is an Established Investigator of the American Heart Association.

\section{Author contributions}

L.-L.H. generated the plasmid constructs used in Figs 1 and 2, designed experiments, performed electrophysiological experiments and analyses for Figs 1 and 2; T.T.Y. performed all electrophysiological experiments and analyses for Figs 3, 4, 5 and 6, performed some electrophysiological experiments and analyses for Fig. 2, designed experiments, made figures and helped write the paper; M.C. generated the constructs used in Figs 3, 4 and 5; K.F. generated the constructs used in Fig. 6; H.M.C. obtained funding, thought of the concept, analysed the data, made figures and wrote the paper.

\section{Additional information}

Supplementary Information accompanies this paper at http://www.nature.com/ naturecommunications

Competing financial interests: The authors declare no competing financial interests.

Reprints and permission information is available online at http://npg.nature.com/ reprintsandpermissions/

How to cite this article: Yang, T. et al. Bio-inspired voltage-dependent calcium channel blockers. Nat. Commun. 4:2540 doi: 10.1038/ncomms3540 (2013). 